\title{
əHow Much Arctic Fresh Water Participates in the Subpolar Overturning Circulation?
}

\author{
Isabela Le Bras, ${ }^{\mathrm{a}, \mathrm{b}}$ Fiamma Straneo, ${ }^{\mathrm{a}}$ Morven Muilwijk, ${ }^{\mathrm{c}, \mathrm{d}}$ Lars H. Smedsrud, ${ }^{\mathrm{c}, \mathrm{d}}$ Feili Li, \\ M. SUSAN LOZIER, ${ }^{\mathrm{e}}$ AND N. PENNY HOLlidAY ${ }^{\mathrm{f}}$ \\ ${ }^{a}$ Scripps Institution of Oceanography, University of California, San Diego, La Jolla, California \\ ${ }^{\mathrm{b}}$ Woods Hole Oceanographic Institution, Woods Hole, Massachusetts \\ ${ }^{\mathrm{c}}$ Geophysical Institute, University of Bergen, Bergen, Norway \\ d Bjerknes Center for Climate Research, Bergen, Norway \\ ${ }^{\mathrm{e}}$ Georgia Institute of Technology, Atlanta, Georgia \\ ${ }^{\mathrm{f}}$ National Oceanography Centre, Southampton, United Kingdom
}

(Manuscript received 6 October 2020, in final form 15 December 2020)

\begin{abstract}
Fresh Arctic waters flowing into the Atlantic are thought to have two primary fates. They may be mixed into the deep ocean as part of the overturning circulation, or flow alongside regions of deep water formation without impacting overturning. Climate models suggest that as increasing amounts of freshwater enter the Atlantic, the overturning circulation will be disrupted, yet we lack an understanding of how much freshwater is mixed into the overturning circulation's deep limb in the present day. To constrain these freshwater pathways, we build steady-state volume, salt, and heat budgets east of Greenland that are initialized with observations and closed using inverse methods. Freshwater sources are split into oceanic Polar Waters from the Arctic and surface freshwater fluxes, which include net precipitation, runoff, and ice melt, to examine how they imprint the circulation differently. We find that $65 \mathrm{mSv}\left(1 \mathrm{~Sv} \equiv 10^{6} \mathrm{~m}^{3} \mathrm{~s}^{-1}\right)$ of the total $110 \mathrm{mSv}$ of surface freshwater fluxes that enter our domain participate in the overturning circulation, as do $0.6 \mathrm{~Sv}$ of the total $1.2 \mathrm{~Sv}$ of Polar Waters that flow through Fram Strait. Based on these results, we hypothesize that the overturning circulation is more sensitive to future changes in Arctic freshwater outflow and precipitation, while Greenland runoff and iceberg melt are more likely to stay along the coast of Greenland.
\end{abstract}

SIGNIFICANCE STATEMENT: The Atlantic's overturning circulation is a vast system of currents that redistributes heat, salt, and carbon, stabilizing Earth's climate. The water in this circulation system cools and sinks into the deep ocean in the high-latitude North Atlantic, where freshwater is also introduced to the system through river runoff from the Arctic, precipitation, and ice melt. We use new observations to quantify how this freshwater moves through the ocean. As Earth warms due to anthropogenic climate change, freshwater flows will increase, potentially triggering a fundamental shift in the overturning circulation and climate system. Our results suggest that the overturning circulation is more sensitive to changes in Arctic freshwater and precipitation than Greenland melt.

KEYWORDS: Arctic; North Atlantic Ocean; Conservation equations; Meridional overturning circulation; Ocean circulation; Inverse methods

\section{Introduction}

As Earth warms due to anthropogenic climate change, inputs of freshwater to the subpolar North Atlantic are expected to increase. The Greenland ice sheet is melting at an accelerating rate, the hydrological cycle is intensifying, and Arctic permafrost and sea ice melt are projected to continue (Shepherd et al. 2020; Stroeve and Notz 2018; IPCC 2019). It has long been thought that the Atlantic meridional overturning circulation (AMOC), which stabilizes Earth's climate, is critically sensitive to increasing high-latitude freshwater sources (Weijer et al. 2019), yet our understanding of how freshwater moves through the Atlantic circulation in our present climate is limited.

We know that freshwater participates in the overturning circulation because the AMOC's lower limb is fresher than its

¿ Denotes content that is immediately available upon publication as open access.

Corresponding author: Isabela Le Bras, ilebras@whoi.edu upper limb (Stommel 1961). At the same time, it is clear that some freshwater is not mixed into the deep ocean, as fresh boundary currents flow along the shelves of Greenland and Labrador (de Steur et al. 2017; Le Bras et al. 2018; Myers et al. 2009; Florindo-López et al. 2020). This partitioning, and how it may change, has been explored in numerical ocean models (e.g., Böning et al. 2016; Dukhovskoy et al. 2016; Wang et al. 2018). However, the baseline of these freshwater pathways has not been comprehensively established from observations.

In this study, we seek to quantify the amount of freshwater that participates in the subpolar overturning circulation by closing budgets of volume, salt, and heat. Our budget domain includes the eastern subpolar North Atlantic and the Nordic Seas (Fig. 1), regions where the bulk of the waters carried in the AMOC lower limb are formed (Chafik and Rossby 2019; Lozier et al. 2019; Huang et al. 2020). The southern boundary of our domain is the Overturning in the Subpolar North Atlantic Program (OSNAP) East array, which spans from southern Greenland to northern Scotland at approximately $60^{\circ} \mathrm{N}$ (Lozier et al. 2017). The domain is closed in the north at Fram Strait and the Barents Sea Opening, where long-term 


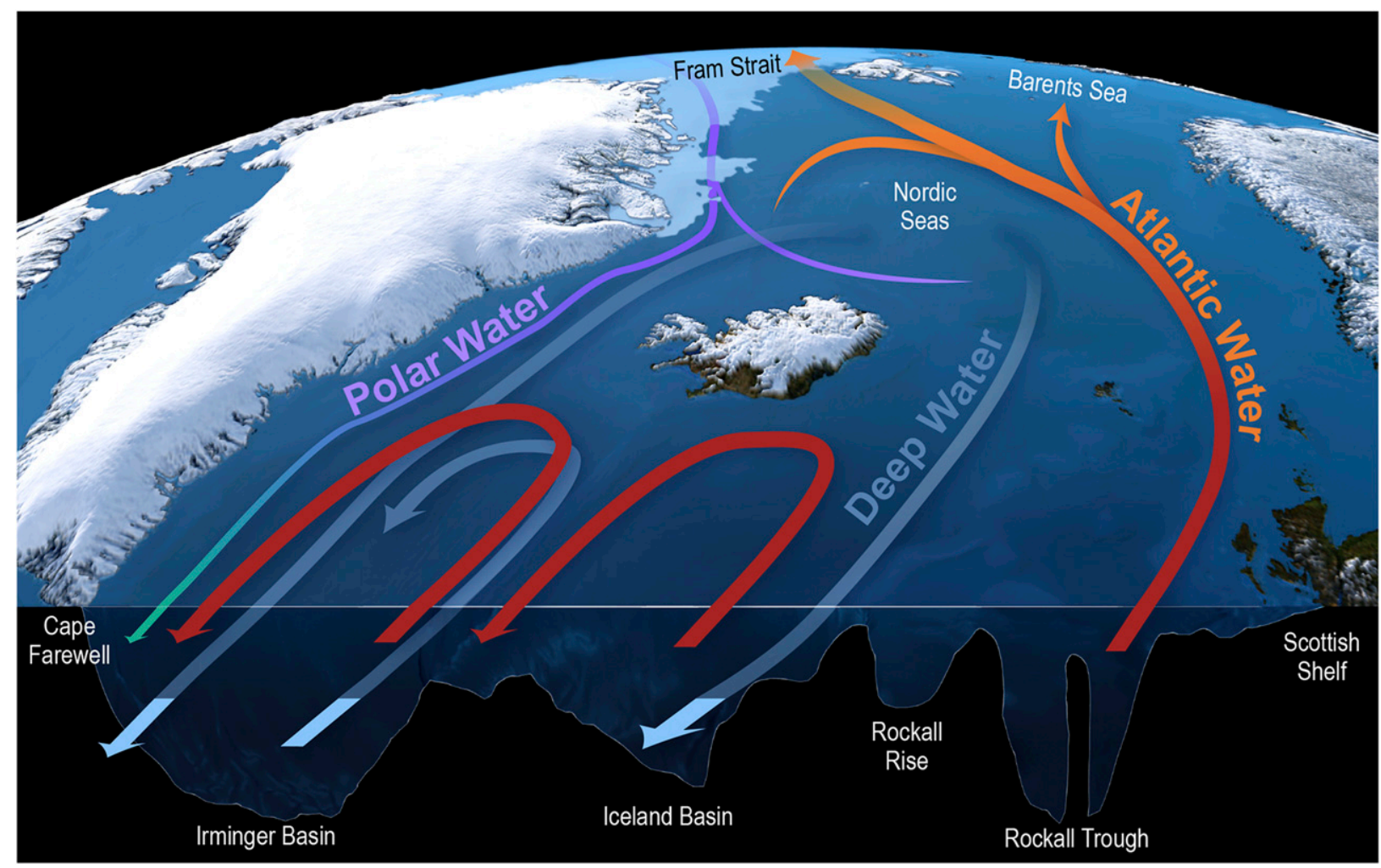

FIG. 1. Schematic of the study region with a cutout at the OSNAP East section. The locations of the Fram Strait and Barents Sea Opening northern boundaries are indicated. Red/orange arrows depict warm, salty Atlantic Water; the light blue arrows depict cold, less salty, dense Deep Waters; and the purple/green arrows depict cold, fresh, light Polar Waters.

observations are also available (Ingvaldsen et al. 2004; Budéus et al. 2008; Beszczynska-Möller et al. 2012; de Steur et al. 2014; Tsubouchi et al. 2012, 2018).

Freshwater enters this region through multiple avenues. Fresh Polar Waters and sea ice flow into the Nordic Seas through Fram Strait (de Steur et al. 2017). Freshwater flux from the Greenland ice sheet enters the region through glacial fjords as runoff and icebergs (Bamber et al. 2018). Finally, precipitation and evaporation over the North Atlantic also alter the water cycle in this critical deep water formation region. Our budget domain was chosen to better understand how fresh Arctic water masses, freshwater fluxes from Greenland, and sub-Arctic air-sea fluxes have imprinted the circulation differently in the last two decades. This will inform how changes in each freshwater source may affect the circulation in the future.

To quantitatively compare oceanic freshwater transports and near-zero salinity freshwater sources, such as ice melt and precipitation, a closed budget must be formed (e.g., Bacon et al. 2015; Schauer and Losch 2019). Without a closed budget, it can be misleading to compare oceanic freshwater transports, which depend on a reference salinity, to zero salinity freshwater sources, which are independent of reference salinity. In this study, we identify near-zero salinity freshwater sources as surface freshwater fluxes (SFW) to distinguish them from the term "fresh water," which is used ambiguously in the oceanographic literature. SFW includes runoff from Greenland ice sheet melt and rivers, iceberg melt, net precipitation, and sea ice melt.

A useful way to conceptualize the water mass transformation in this region is to divide it into overturning and estuarine circulations. The overturning circulation describes the transformation of northward flowing warm, salty Atlantic Waters into denser, colder and less saline deep waters. The estuarine circulation is the transformation of Atlantic Waters into the cold, fresh, light surface outflows from the Arctic. The overturning circulation is a vertical circulation cell associated with densification through cooling, while the estuarine circulation is a horizontal circulation cell associated with lightening through freshening (Fig. 2). Though it is not commonly referenced in climate model based studies of the AMOC, the idea that the Arctic and Nordic Seas exhibit this "double estuary" behavior is not new (e.g., Stigebrandt 1985; Carmack 2007; Hansen et al. 2008; Rudels 2010; Eldevik and Nilsen 2013; Lambert et al. 2016; Østerhus et al. 2019).

Eldevik and Nilsen (2013) apply this framework at the Greenland-Scotland ridge, where the circulation is confined to narrow straits. They estimate that the roughly $8.5 \mathrm{~Sv}(1 \mathrm{~Sv} \equiv$ $10^{6} \mathrm{~m}^{3} \mathrm{~s}^{-1}$ ) of Atlantic Waters flowing northward at the ridge are converted to about $6 \mathrm{~Sv}$ of denser Overflow Water (overturning transformation) and $2.5 \mathrm{~Sv}$ of cold, fresh, lighter Polar Water (estuarine transformation). Eldevik and Nilsen (2013) test the sensitivity of these transformations in an analytical model based on volume, salt, and heat budgets and find that the 
54 mSv SFW

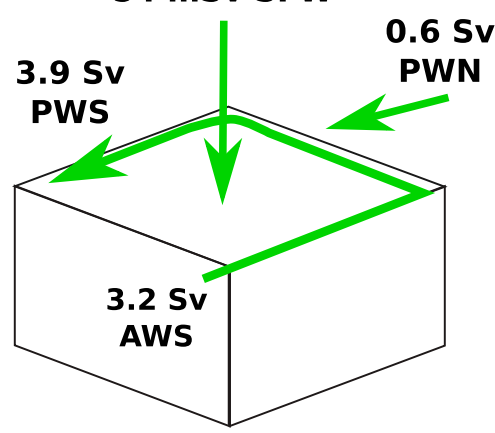

Estuarine (PWS)
65 mSv SFW

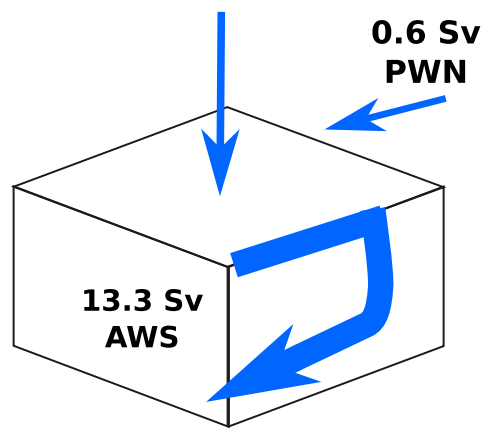

13.9 Sv DWS

Overturning (DWS)

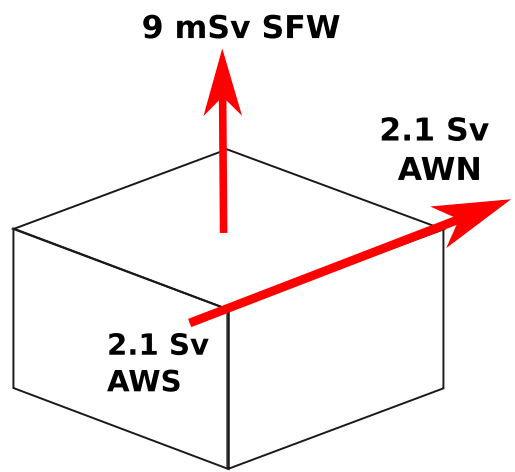

AW Throughflow (AWN)

FIG. 2. Schematic of the freshwater budget decomposition into the three components of the circulation. The listed transports are the inverse model solutions (Table 1, stars in Fig. 7). The water masses are Atlantic Water (AW), Polar Water (PW), and Deep Water (DW); the suffixes "S" and "N" refer to the southern and northern boundaries of the domain, respectively. Surface freshwater (SFW) includes net precipitation, sea ice melt, runoff, and iceberg melt.

presence of the estuarine circulation stabilizes the overturning circulation.

Here, we apply a similar framework to the circulation measured by OSNAP in the eastern subpolar gyre. We are motivated by the fact that the circulation at this latitude is more representative of the large-scale Atlantic meridional overturning circulation than the circulation at the GreenlandScotland ridge (Dickson et al. 1990; Pickart et al. 2003; Yashayaev and Dickson 2008; Lozier et al. 2019; Petit et al. 2020). In contrast to Eldevik and Nilsen (2013), our goal is not to diagnose the sensitivity of the circulation, but to constrain how freshwater moves through the overturning and estuarine components of the circulation in a closed budget system. To account for the net flow into the Arctic north of our domain, as well as some Arctic transformations of Atlantic Waters, we also include an Atlantic Water throughflow in our framework. We decompose the circulation into the overturning, estuarine, and Atlantic Water throughflow components in such a way that summing them together yields the net circulation.

We define water masses that reflect these three components of the circulation and build volume, salt, and heat budgets for each component. Our budgets are initialized using observations and closed using linear inverse methods, which are tools for diagnosing oceanic transports and transformations given a set of constraints and unknowns (Wunsch 1978). Recent applications of inverse methods near our study region include Tsubouchi et al. (2012, 2018, 2020), who apply inverse methods to investigate Arctic mass and salt budgets, and Mackay et al. (2020), who diagnose water mass transformations north of the OSNAP line. Tsubouchi et al. (2012, 2018, 2020) and Mackay et al. (2020) treat reference velocities and mixing terms as principal unknowns, whereas our approach is similar to that of Mauritzen (1996), who treats water mass transports as unknowns in diagnosing detailed water mass transformation pathways in the Nordic Seas. As our focus is on the participation of freshwater in the large-scale, steady-state circulation, we use a much simpler set of water masses than Mauritzen (1996).
Our overarching aim is to quantify how much Arctic freshwater participates in the subpolar overturning circulation. To this end, we build steady-state volume, salt, and heat budgets, which are split into water masses that represent the primary components of the circulation, including the overturning circulation. We examine which sources of freshwater likely participate in the overturning circulation by identifying how fresh Polar Waters from the Arctic and surface freshwater fluxes are partitioned between the components of the circulation in our closed budget system. By improving our understanding of the mean state, we hope to provide a baseline for predictions of what climate change will bring.

This manuscript is organized as follows: in section 2 we document the datasets used in this study; in section 3 we outline our methods, including the water mass decomposition, inverse method, and budget partitioning; in section 4 we detail the initial conditions of our budgets of volume, salt, and heat; in section 5 we present our inverse model budget results, including the partitioning of freshwater between the overturning and estuarine circulations; and in section 6 we discuss the implications of this work in a broader context. The sensitivities to our primary uncertainties are documented in the appendix.

\section{Data}

Our budget domain is bounded by two different observationbased datasets: the Fram Strait and Barents Sea Opening dataset (October 2004-May 2010; Tsubouchi et al. 2019) and the OSNAP East dataset (September 2014-May 2018; Lozier et al. 2019). Though these records are not contemporaneous, we find that their mean values provide a relevant approximation of the steady state, as discussed in the appendix.

\section{a. OSNAP East}

The OSNAP East dataset consists of monthly mean property (temperature and salinity) and velocity fields extending from Greenland to Scotland (September 2014-May 2018; Lozier et al. 2019). Properties and velocity were measured directly by moored 
arrays on the continental boundaries, in the Iceland Basin and in the Rockall Trough. Between mooring arrays, gridded property fields were synthesized from Argo profile data, OSNAP gliders, the World Ocean Atlas 2018 climatology, and shipboard hydrographic data using objective analysis. Geostrophic velocities were calculated from the property fields away from the moorings; these were referenced to the topmost measurement of deep moorings where available, and time mean surface velocities from satellite altimetry otherwise. The unmeasured flow above the Labrador Shelf was filled with an ensemble-mean velocity climatology from ocean or ocean-sea ice models and ocean reanalysis ( $\mathrm{Li}$ et al. 2020, manuscript submitted to Nat. Commun.). Ekman velocities, which are very small along this line, were calculated from ERA5 winds. The net transport across OSNAP East was adjusted to total $1.6 \mathrm{~Sv}$ at each time step to compensate for the estimated southward flow through Davis Strait west of Greenland (Li et al. 2017). The adjustment was made by adding a constant velocity to areas that are referenced to time mean surface velocities, so that the adjustment can be thought of as a time-varying barotropic velocity. The Bering Strait throughflow, which accounts for about $1 \mathrm{~Sv}$ of the southward 1.6 Sv flowing through Davis Strait (Woodgate 2018), is not included in the OSNAP product and has been found not to impact overturning variability (Lozier et al. 2019). Li et al. (2017) discuss the methodology and uncertainty of this product in the context of Observing System Simulation Experiments. In this study, we use the published OSNAP East dataset as an initial condition and enforce overall volume balance in our domain, which allows for a net northward throughflow. The initial conditions at the northern boundary account for the Bering Strait throughflow as they are based on a closed Arctic budget and the OSNAP East initial conditions are adjusted to accommodate this in our inverse budget framework (section 5). Hence, the Bering Strait throughflow is accounted for in our results.

\section{b. Fram Strait and Barents Sea Opening}

The Fram Strait and Barents Sea Opening monthly mean property and velocity fields are inverse model solutions generated in the context of volume and salt budgets for the Arctic Ocean to the north of these passages as well as the Davis and Bering Straits (October 2004-April 2010; Tsubouchi et al. 2012, 2018, 2019). The fields are based primarily on moored arrays which measure properties and velocity directly (de Steur et al. 2014; Beszczynska-Möller et al. 2012; Ingvaldsen et al. 2004). Repeat CTD section data are also used in the Barents Sea Opening. Data gaps longer than 30 days are filled using the climatological seasonal cycle, and the unobserved portions of the continental shelves are filled with zero velocity. It is assumed that there is no stratification above each shallowest mooring instrument. Limited observations indicate that there is some northward flow on the western shelf of Fram Strait in the summer (de Steur et al. 2009). However, this may be compensated for by the fact that salinity is likely overestimated by the subsurface observations, and the net error is unclear (Tsubouchi et al. 2018). The box inverse model is set up to solve for reference velocities, sea ice speeds, freshwater fluxes, and diapycnal velocities between prescribed isopycnal layers, as detailed in Tsubouchi et al. $(2012,2018)$.

\section{c. NorESM climate model}

We use model monthly mean fields of velocity, salinity and temperature from January 2000 to December 2018 to examine the impact of interannual changes in water mass transport and properties on our results. These fields are from the forced global ice-ocean configuration of the second version of the Norwegian Earth System Model (NorESM2-LM, referred to as NorESM in this study; Bentsen et al. 2019). The general description of the model predecessor, NorESM1, is provided by Bentsen et al. (2013), while the updated version of the model in a fully coupled configuration is presented by Seland et al. (2020). The ocean model, Bergen Layered Ocean Model (BLOM), is an updated version of the Miami Isopycnic Coordinate Ocean Model (MICOM) used in NorESM1. BLOM consists of 53 nearisopycnic interior layers and variable density layers in the surface well-mixed boundary layer. A tripolar grid is used, which allows for higher spatial resolution in the high latitudes. At the equator, the grid resolution is $1^{\circ}$ zonally and $1 / 4^{\circ}$ meridionally. The grid gradually becomes more isotropic as latitude increases: the typical horizontal resolution in the Nordic Seas is $40 \mathrm{~km}$. The sea ice model is version 5.1.2 of the Los Alamos Sea Ice Model (CICE5.1.2; Hunke et al. 2015) configured with eight layers of ice and three of snow, using the same horizontal grid as the ocean model. A NorESM2-specific change to CICE is the inclusion of the effect of wind drift of snow into ocean following Lecomte et al. (2013). NorESM1 was evaluated relative to hydrographic observations in the Nordic Seas over the last century by Muilwijk et al. (2018). Note that NorESM1 was forced by an adjusted version of the twentieth-century atmospheric reanalysis forcing (Compo et al. 2011), whereas the updated NorESM2-LM is forced by the Japanese 55-year Reanalysis (Tsujino et al. 2018). The simulations are provided as part of the CMIP6 contribution for the OMIP experiments (Ocean Model Intercomparison Project; Griffies et al. 2016).

\section{d. Reanalysis products}

We examine net precipitation and heat fluxes from several reanalysis products: the Japanese 55-year Reanalysis for driving ocean-sea ice models (JRA55-do; Tsujino et al. 2018), the European Centre for Medium-Range Weather Forecasts (ECMWF) fifth generation reanalysis (ERA5; Dee et al. 2011; Copernicus Climate Change Service 2017), and the National Centers for Environmental Prediction Climate Forecast System (NCEP-CFS) version 2 (Saha et al. 2014) and reanalysis version 1 (Saha et al. 2010b). We extracted monthly mean evaporation, precipitation, and heat flux data from each of these products from January 2000 to December 2018. We do not consider the difference between liquid and solid precipitation. Heat flux was calculated as the sum of latent, sensible, shortwave, and longwave fluxes. Fluxes from the atmosphere into the ocean are defined as positive.

JRA55-do version 1.4.0 is the reanalysis product used to force NorESM; it extends from 1958 to present, is updated annually, and implemented widely in ocean-sea ice models (Tsujino et al. 2018). JRA55 (Kobayashi et al. 2015), which is at the core of 
JRA55-do, is adapted from the second Japanese global atmospheric reanalysis produced by the Japanese Meteorological Society, and is available on a refined $\approx 55-\mathrm{km}$ grid. In this study, we estimate the total surface freshwater fluxes, which include net precipitation, sea ice melt, iceberg melt, and runoff, from JRA55do and its implementation in NorESM (section 4b). The remaining reanalysis products are used for comparison.

ERA5 has nominal $31-\mathrm{km}$ resolution; we accessed $0.25^{\circ}$ gridded fields. NCEP-CFS reanalysis version 1 is available until 2011 (Saha et al. 2010b). NCEP-CFS version 2 is the current forecasting model updated in real time. The differences between the versions are detailed in Saha et al. (2014). We combine version 1 from 2000 to 2010 with version 2 from 2011 to 2018 in our analysis. Both were accessed as monthly products gridded to $0.5^{\circ}$ resolution.

\section{Methods}

To diagnose freshwater pathways in the subpolar and Nordic Seas, we partition the circulation into water masses which represent the primary large-scale transformations in the region (Figs. 1 and 2). At the southern boundary of our domain, OSNAP East, the circulation is divided into three water masses: Atlantic Water South (AWS) is the warm, salty water mass flowing northward at the surface; it is compensated by a deep, cold, less salty flow of Deep Water South (DWS, overturning transformation), and a cold, fresh surface flow of Polar Water South just east of Greenland (PWS, estuarine transformation). At the northern boundary, the waters are separated into warm, salty Atlantic Water North (AWN), which has a net northward flow, and cold, fresh Polar Water North (PWN), which flows southward along the western edge of Fram Strait.

We determine the salinity, temperature, and volume transport of each water mass and use these as initial conditions in an inverse model framework (sections $3 a$ and $3 b$ ). The remaining elements of our budgets are heat flux $Q$ and surface freshwater flux (SFW), which includes runoff, iceberg melt, net precipitation and sea ice melt. Finally, starting from the inverse model solution, we solve for the portions of the two primary freshwater sources (SFW and PWN) which participate in each component of the circulation (section 3c).

\section{a. Water mass budget framework}

We define water masses at the boundaries of our domain, and write budgets of volume, salt, and heat in terms of representative transports, salinities, and temperatures for each water mass. The transport for a water mass $U_{i}$ is the boundary normal velocity, $\mathbf{u} \cdot \mathbf{n}$, integrated over the area that defines a given water mass $i$ :

$$
U_{i}=\iint_{i} \mathbf{u} \cdot \mathbf{n} d A
$$

The transport-weighted salinities and temperatures are

$$
S_{i}=\frac{\iint_{i} S \mathbf{u} \cdot \mathbf{n} d A}{\iint_{i} \mathbf{u} \cdot \mathbf{n} d A},
$$

$$
T_{i}=\frac{\iint_{i} T \mathbf{u} \cdot \mathbf{n} d A}{\iint_{i} \mathbf{u} \cdot \mathbf{n} d A},
$$

where $S$ is Absolute Salinity and $T$ is Conservative Temperature, derived using the TEOS-10 Gibbs Seawater (GSW) toolbox (McDougall and Barker 2011). Surface freshwater fluxes (SFW) are treated as a water mass with $S=0$ and $T=0$. The water mass salinities and temperatures are constructed in this way so that the steady-state budgets of volume, salt and heat can be written:

$$
\begin{aligned}
\sum_{i} U_{i} & =0, \\
\sum_{i} S_{i} U_{i} & =0, \\
\sum_{i} T_{i} U_{i} & =\frac{Q}{\rho_{o} c_{p}},
\end{aligned}
$$

where $Q$ is the area integrated heat flux; we assume a constant for the density of seawater, $\rho_{o}=1025 \mathrm{~kg} \mathrm{~m}^{-3}$; and the specific heat capacity of seawater is $c_{p}=3850 \mathrm{~J} \mathrm{~kg}^{-1}{ }^{\circ} \mathrm{C}^{-1}$. Storage terms have been neglected because we are assuming a steady state.

\section{b. Inverse model}

We use an inverse model framework to solve for the water mass transports, net surface freshwater flux into, and net heat flux out of our budget domain, and represent each of these as $\chi_{i}$ in this section. We separate each unknown $\chi_{i}$ into an initial estimate and deviations from that estimate, $\chi_{i}=\overline{\chi_{i}}+\chi_{i}^{\prime}$; the deviations from the initial estimates $\chi_{i}^{\prime}$ are the unknowns in our systems of equations. Though we test the sensitivity of the model to water mass properties (see appendix), in each model run the water mass salinities and temperatures are kept constant.

Following Wunsch (1996), the weighted inverse model equations are represented in matrix form:

$$
\left(\mathbf{W}^{-1} \mathbf{A E}\right)\left(E^{-1} \mathbf{x}\right)=\mathbf{W}^{-1} \mathbf{d},
$$

where A is $M \times N$ and contains the conservation equation operators. Here, $M=3$, the number of conservation equations [Eqs. (1)-(3)]; $N=7$, the number of unknowns (five water masses, surface freshwater fluxes, and heat fluxes); $\mathbf{x}$ is $N \times 1$ and is the vector of unknowns (made up of all $\chi_{i}^{\prime}$ ); $\mathbf{d}=\mathbf{A} \overline{\mathbf{x}}$ is $M \times 1$, where $\overline{\mathbf{x}}$ is the $N \times 1$ vector of initial estimates (made up of all $\overline{\chi_{i}}$ ).

The constraints are weighted using a square row weighting matrix $\mathbf{W}(M \times M)$, and the unknowns are weighted using a square column weighting matrix $\mathbf{E}(N \times N)$. The weighting matrix $\mathbf{W}$ normalizes the budget equations so that they are on the same order; we choose $\mathbf{W}$ to be a diagonal matrix so that the salt conservation equation [Eq. (2)] is normalized by $1 / S_{\text {norm }}$ and the heat conservation equation [Eq. (3)] is normalized by $1 / T_{\text {norm }}$. We choose representative scaling values of $S_{\text {norm }}=$ $35 \mathrm{~g} \mathrm{~kg}^{-1}$ and $T_{\text {norm }}=10^{\circ} \mathrm{C}$.

Matrix $\mathbf{E}$ allows each unknown to be weighted differently. Each unknown is weighted by its standard error: the standard deviation of the time series divided by the square root of the effective degrees of freedom. We assume that there are four degrees of freedom per year, as 
the seasonal cycle is the shortest resolved time scale in our monthly data.

The weighted equations can be simplified by substituting $\tilde{\mathbf{A}}=\mathbf{W}^{-1} \mathbf{A E}, \tilde{\mathbf{x}}=\mathbf{E}^{-1} \mathbf{x}$, and $\tilde{\mathbf{x}}=\mathbf{W}^{-1} \mathbf{d}$ to form a new set of equations,

$$
\tilde{\mathbf{A}} \tilde{\mathbf{x}}=\tilde{\mathbf{d}} .
$$

We solve this using singular value decomposition, i.e., $\tilde{\mathbf{A}}=\mathbf{U} \mathbf{\Lambda} \mathbf{V}^{\mathrm{T}}$, where $\mathbf{U}$ and $\mathbf{V}$ are square eigenvector matrices, $\boldsymbol{\Lambda}$ is a rectangular matrix with eigenvalues on the diagonal, and the pseudoinverse of $\tilde{\mathbf{A}}$ is $\tilde{\mathbf{A}}^{-1}=\mathbf{V} \boldsymbol{\Lambda}^{-1} \mathbf{U}^{\mathrm{T}}$. The solution to the weighted equations can hence be written,

$$
\mathbf{x}=\mathbf{E V} \boldsymbol{\Lambda}^{-1} \mathbf{U}^{\mathrm{T}} \mathbf{W}^{-1} \mathbf{d}
$$

Though we solve for deviations from the initial conditions, we present the total solutions including the initial conditions throughout, i.e., $\chi_{i}=\overline{\chi_{i}}+\chi_{i}^{\prime}$. We present the solution uncertainties, or a posteriori uncertainties, as the diagonal component of the error covariance matrix (Wunsch 1996):

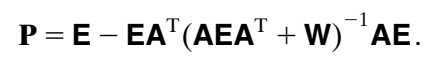

\section{c. Splitting the budget into circulation components}

The three water mass products we define, PWS, DWS, and AWN, correspond to the three primary components of the circulation in our study region: the estuarine, overturning, and Atlantic Water throughflow circulations (Fig. 2). We assume that a portion of the inflowing AWS and SFW flows into each, while PWN only participates in the estuarine and overturning components. This choice is based on geographical considerations: Polar Water flows along the eastern boundary of Greenland and can be stirred into deep water formation regions, but is not thought to interact with the Atlantic Water throughflow (de Steur et al. 2017; Schauer et al. 2008). The following volume and salt conservation equations illustrate this partitioning.

1) The estuarine circulation, which produces PWS:

$$
\begin{gathered}
(1-\epsilon) U_{\mathrm{PWN}}+\alpha U_{\mathrm{AWS}}+\delta U_{\mathrm{SFW}}=-U_{\mathrm{PWS}} \\
(1-\epsilon) S_{\mathrm{PWN}} U_{\mathrm{PWN}}+\alpha S_{\mathrm{AWS}} U_{\mathrm{AWS}}=-S_{\mathrm{PWS}} U_{\mathrm{PWS}}
\end{gathered}
$$

2) The overturning circulation, which produces DWS:

$$
\begin{gathered}
\epsilon U_{\mathrm{PWN}}+\beta U_{\mathrm{AWS}}+\gamma U_{\mathrm{SFW}}=-U_{\mathrm{DWS}}, \\
\epsilon S_{\mathrm{PWN}} U_{\mathrm{PWN}}+\beta S_{\mathrm{AWS}} U_{\mathrm{AWS}}=-S_{\mathrm{DWS}} U_{\mathrm{DWS}} .
\end{gathered}
$$

3) The Atlantic Water throughflow, which produces AWN:

$$
\begin{aligned}
(1-\alpha-\beta) U_{\mathrm{AWS}}+(1-\delta-\gamma) U_{\mathrm{SFW}} & =-U_{\mathrm{AWN}} \\
(1-\alpha-\beta) S_{\mathrm{AWS}} U_{\mathrm{AWS}} & =-S_{\mathrm{AWN}} U_{\mathrm{AWN}}
\end{aligned}
$$

All Greek letters represent a unitless fraction. Summing the above volume conservation equations and salt conservation equations yields Eqs. (1) and (2). Solving for the fractions of SFW that participates in each component $(\delta, \gamma)$ in terms of the partitioning of PWN between the estuarine and overturning circulation components $(\epsilon)$ yields:

$$
\begin{aligned}
& \delta U_{\mathrm{SFW}}=(1-\epsilon) U_{\mathrm{PWN}}\left(\frac{S_{\mathrm{PWN}}}{S_{\mathrm{AWS}}}-1\right)+U_{\mathrm{PWS}}\left(\frac{S_{\mathrm{PWS}}}{S_{\mathrm{AWS}}}-1\right), \\
& \gamma U_{\mathrm{SFW}}=\epsilon U_{\mathrm{PWN}}\left(\frac{S_{\mathrm{PWN}}}{S_{\mathrm{AWS}}}-1\right)+U_{\mathrm{DWS}}\left(\frac{S_{\mathrm{DWS}}}{S_{\mathrm{AWS}}}-1\right) .
\end{aligned}
$$

The fraction of SFW contributing to the formation of AWN $(1-\delta-\gamma)$ is not impacted by the way that PWN is split between the overturning and estuarine circulation components $\epsilon$, as PWN does not participate in the AW throughflow.

\section{Budget components}

\section{a. Water mass decompositions}

The oceanic water mass components of our budget are defined using isopycnal surfaces and geographic boundaries (Fig. 3). The isopycnal used to separate water masses at OSNAP East is the time mean isopycnal of maximum overturning, $\sigma_{\theta}=27.56 \mathrm{~kg} \mathrm{~m}^{-3}$ (Lozier et al. 2019; Li et al. 2020, manuscript submitted to Nat. Commun.). This isopycnal is defined as that which maximizes the compensating flow in the upper and lower limbs in density space. In studies reporting on the overturning measured by OSNAP (e.g., Lozier et al. 2019), this isopycnal changes at each time step. In this study, we use the time mean isopycnal of maximum overturning to eliminate changes in this dividing isopycnal as a source of water mass density changes. Our results are not critically sensitive to this choice; the OSNAP East isopycnal of maximum overturning has a standard deviation of $0.05 \mathrm{~kg} \mathrm{~m}^{-3}$.

The waters below the isopycnal of maximum overturning at OSNAP East are defined as DWS (Fig. 3). DWS is composed of overflow waters formed in the Nordic Seas, which are modified by entrainment, as well as intermediate waters formed by convection in the Labrador, Irminger, and Iceland Basins (Petit et al. 2020). These intermediate waters, some of which are formed to the south of the OSNAP East line, recirculate throughout the eastern subpolar gyre (Fig. 3). The DWS water mass can be thought of as a single water mass which flows southward with the net volume transport below the isopycnal of maximum overturning. This water mass has an associated salinity and temperature such that when multiplied by the net volume transport they equal the net salinity and temperature transports, respectively (section 3a). Any recirculations of waters with the same properties will cancel out and any water mass transformation will be reflected in the net water mass properties.

The waters above the isopycnal of maximum overturning at OSNAP East are separated into AWS and PWS at $40^{\circ} \mathrm{W}$, which corresponds to the mean zero velocity contour (Fig. 3). West of $40^{\circ} \mathrm{W}$, the East Greenland Current system carries cold, fresh PWS southward. East of $40^{\circ} \mathrm{W}$, the flow is a complicated set of cyclonic recirculations within each subbasin of the eastern subpolar North Atlantic. AWS can be thought of as a single northward flowing water mass with water mass properties that take recirculations into account, as explained above. For example, the net AWS water mass is fresher than Atlantic Water in the eastern subpolar 


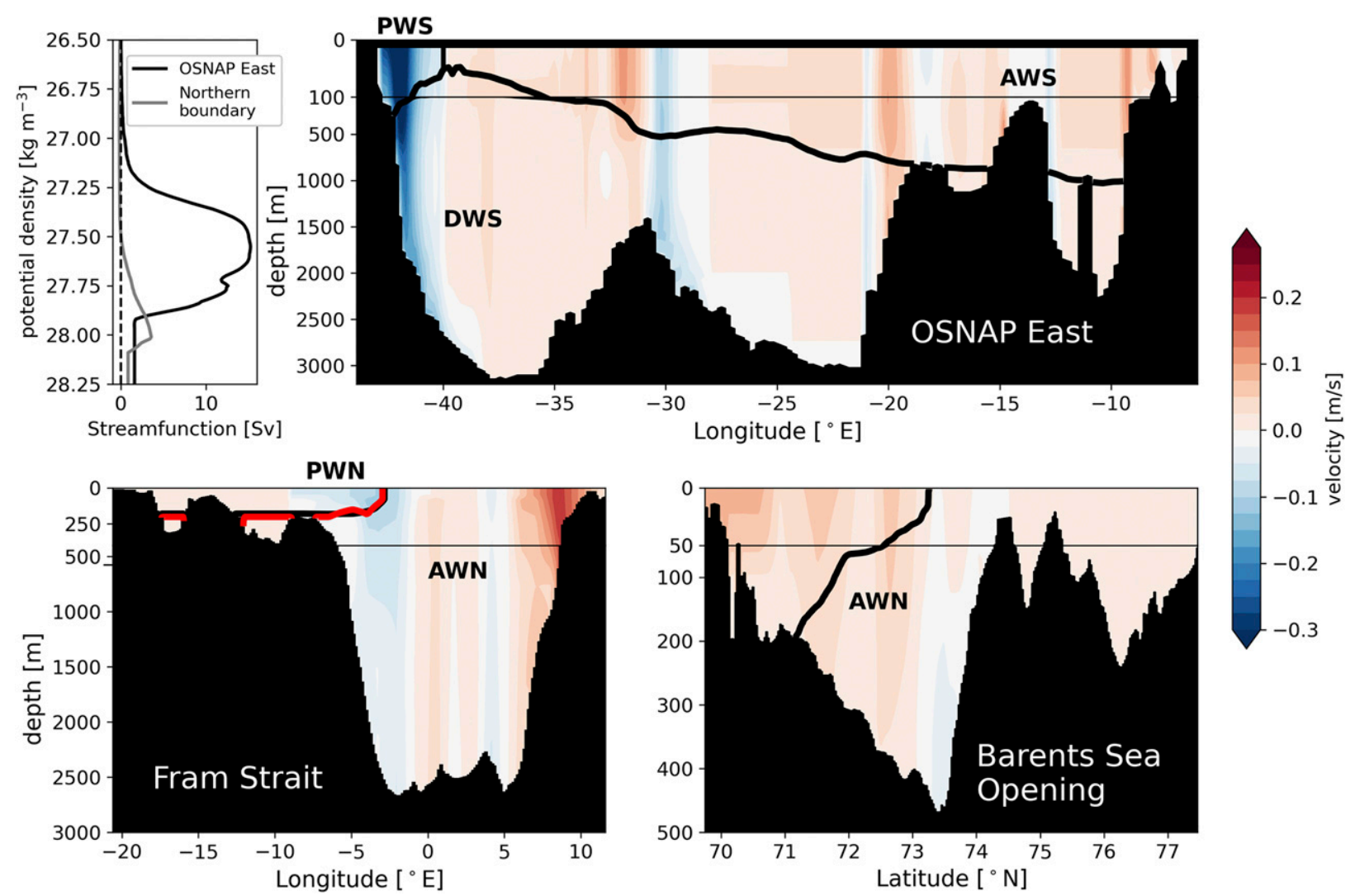

FIG. 3. Observed annual mean streamfunctions in (top left) density space and cross-track velocity sections at (top right) OSNAP East (August 2014-May 2018), (bottom left) Fram Strait, and (bottom right) Barents Sea Opening (October 2004-April 2010). The geographic distributions of each water mass are labeled. Thick black lines denote the mean position of the isopycnal of maximum overturning determined at the OSNAP East Section $\left(\sigma_{\theta}=27.56 \mathrm{~kg} \mathrm{~m}^{-3}\right)$; the thick red line shown in the Fram Strait panel is the mean position of the $T=0^{\circ} \mathrm{C}$ isotherm above $500 \mathrm{~m}$. Note that the $y$ axis is stretched near the surface of each panel, as indicated by the thin horizontal line.

gyre due to lateral stirring and potentially spill jet entrainment (Lozier et al. 2019; von Appen et al. 2014).

At the northern boundary, we define PWN as the cold and fresh surface waters flowing southward on the western boundary of Fram Strait, and the remaining waters, including all waters in the Barents Sea Opening, as AWN. We use the $0^{\circ} \mathrm{C}$ isotherm above $500 \mathrm{~m}$ to define PWN in Fram Strait (Rudels et al. 2008; de Steur et al. 2014). Interestingly, the position of this isotherm coincides with the OSNAP East isopycnal of maximum overturning (Fig. 3). As a consequence, PWN and PWS have similar densities (Fig. 4).

Many other water masses have been identified in Fram Strait, such as transformed Atlantic Waters, Intermediate Waters, and Deep Waters (e.g., Mauritzen 1996; BeszczynskaMöller et al. 2012; Tsubouchi et al. 2018), which we include in our AWN water mass for simplicity. As it is not a focus of this study, the overturning circulation to the north of our domain is hence somewhat artificially included in this circulation component. Note that this overturning cell is much weaker and involves denser waters than the overturning at OSNAP East (Fig. 3). A recent study has found that the densest overflow waters form in the Greenland Sea (Huang et al. 2020), which is within our domain, though dense Arctic outflows likely contribute to preconditioning. Some of the overturning to the north of our domain consists of the $2.3 \mathrm{~Sv}$ of warm AW inflow to the Barents Sea that partly returns southward in Fram Strait as cooled water masses (Smedsrud et al. 2013). Because our AWN is composed of cold waters flowing southward in Fram Strait as well as northward flowing warmer and saltier waters, it has large northward temperature and salinity transports. The net AWN water mass has a high temperature, high salinity, and low net volume transport that reflects this circulation. This can be contrasted with the waters flowing north through the shallow Barents Sea Opening, which are significantly cooler and fresher: $2.18 \mathrm{~Sv}$ at $8.4^{\circ} \mathrm{C}$ and $34.7 \mathrm{~g} \mathrm{~kg}^{-1}$.

Our water mass partitioning reflects the simplified threecomponent circulation. To remove seasonal bias, we average transports and properties from each month together before taking the overall mean. From the observations (section 2), we calculate that $19.1 \mathrm{~Sv}$ of warm, salty AWS and 1.2 Sv of cold, fresh PWN flow into the budget domain (Fig. 4). These are transformed into 3.9 Sv of PWS in the estuarine circulation, 13.6 Sv of DWS in the overturning circulation, and $2 \mathrm{~Sv}$ in the AWN throughflow. These observed transports are the initial conditions to our inverse model. All water mass transports are quoted with their standard errors, which are also their inverse model weights, in Table 1 . We describe 

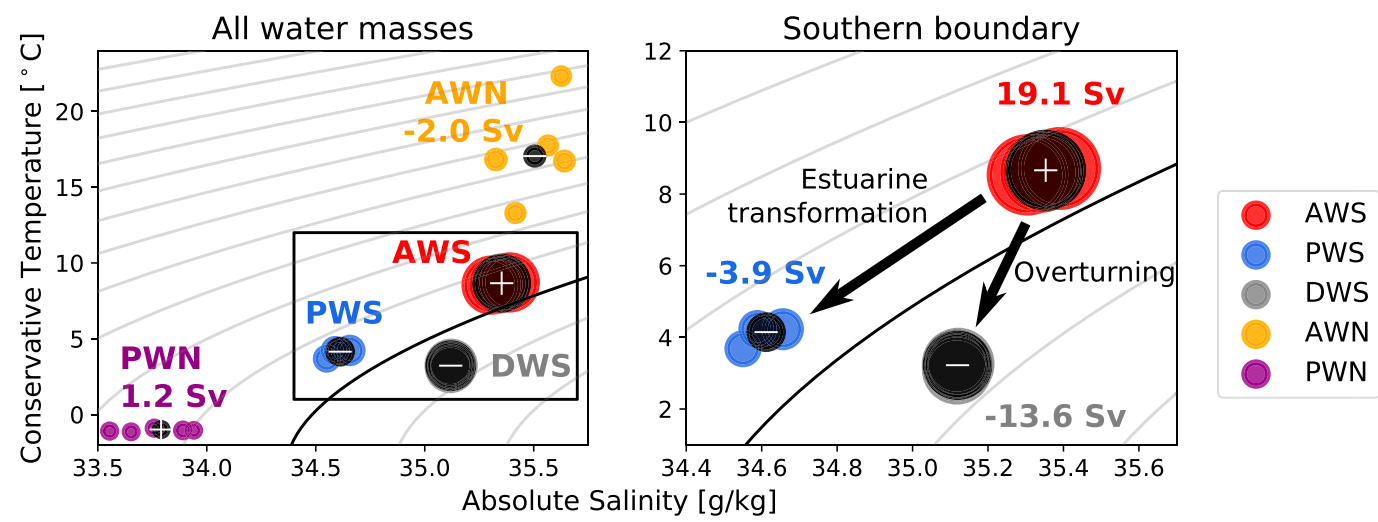

FIG. 4. Observed transport-weighted water mass properties. Colorful circles are January-December single year means, and nearby black dots are full observational record annual mean values. The size of each point is scaled by its transport and full mean transports are labeled. White positive (negative) signs indicate that the water mass is flowing into (out of) the budget domain. The overturning and estuarine transformations at OSNAP East are highlighted. Black contours denote the $\sigma_{\theta}$ isopycnal of maximum overturning, and gray $\sigma_{\theta}$ contours are separated by $0.4 \mathrm{~kg} \mathrm{~m}^{-3}$. The black box in the left panel indicates the axis range of the right panel.

the remaining components of the budget next: surface freshwater and heat fluxes.

\section{b. Surface freshwater fluxes}

Freshwater enters the study volume through the surface as sea ice melt, runoff from rivers and Greenland's glaciers, iceberg melt, and precipitation, which is countered by evaporation (Fig. 5). The sum of all these surface freshwater fluxes (SFW) is treated as one component of our budget. The JRA55-do SFW, totaling $106 \pm 12 \mathrm{mSv}$, is used as the inverse model initial condition as it includes all sources and provides a self-consistent spatial distribution. We refer to the near-zero salinity sources to the budget domain as surface freshwater fluxes, but note that runoff from Greenland and iceberg melt can enter below the surface. In this section we describe each freshwater source and compare JRA55-do to other reanalysis products.

We find that precipitation minus evaporation from JRA55-do and ERA5 agree reasonably well: they both exhibit weak seasonal cycles which peak in September and their annual means are 12 and $38 \mathrm{mSv}$, respectively (Fig. 5a). The NCEP-CFS annual mean precipitation minus evaporation is much larger at $132 \mathrm{mSv}$ and its seasonal cycle peaks in February. Precipitation and evaporation are not well constrained in this region, both because of a lack of reliable in situ data, and because sea ice complicates remote sensing. Boisvert et al. (2018) also document that NCEP-CFS has higher precipitation than JRA55-do and ERA5, and find that variability between products is particularly high in this region. We use the JRA55-do precipitation minus evaporation value for consistency, and investigate uncertainty related to SFW in the appendix.

Solid sea ice is imported through Fram Strait and melts before exiting the domain. The sea ice freshwater flux we use is the NorESM sea ice model estimate of net sea ice melt and freeze based on JRA55-do, which is implemented as an influx of freshwater with zero salinity (Fig. 5b). Note that in reality sea ice has a nonzero salinity, particularly young sea ice: Fram Strait sea ice salinity is approximated as 4 (Spreen et al. 2020). Accounting for sea ice salinity does not greatly impact our results (appendix). The NorESM annual mean sea ice melt in the domain, $74 \mathrm{mSv}$, agrees well with the Kwok et al. (2004) Fram Strait solid sea ice flux estimate of $70 \mathrm{mSv}$ (1991-98) and the Spreen et al. (2020) estimate of $76 \mathrm{mSv}$ (1992-2014). The NorESM value is on the same order as the Tsubouchi et al. (2018) solution of $51 \mathrm{mSv}$ of solid sea ice export through Fram Strait, which compares favorably with the Spreen et al. (2009) and Ricker et al. (2018) estimates from October to April.

The JRA55-do river runoff fields are based on the Suzuki et al. (2018) dataset. Runoff and iceberg flux from Greenland is added from the Bamber et al. (2018) dataset (1958-2016). After 2016, the 2012-16 climatology from Bamber et al. (2018) is used. Runoff and iceberg melt are distributed over a broad area near the coasts to ensure model stability (Figs. $5 \mathrm{c}$ and 8 ). In nature, runoff enters the water column through subsurface plumes at the base of East

TABLE 1. Observation based steady-state inverse model water mass Absolute Salinities $S$, Conservative Temperatures $T$, initial conditions, and mean solution. The inverse model unknowns are the transports of the oceanic water masses: Atlantic Water (North and South: AWN, AWS), Polar Water (North and South: PWN, PWS), and Deep Water South (DWS), surface freshwater (SFW), and heat fluxes $Q$. Initial conditions are quoted with a priori uncertainties (standard error), and solutions are quoted with a posteriori uncertainties (section 3).

\begin{tabular}{|c|c|c|c|c|c|c|c|}
\hline & AWS & DWS & PWS & PWN & AWN & SFW & $Q$ \\
\hline$S\left(\mathrm{~g} \mathrm{~kg}^{-1}\right)$ & 35.35 & 35.12 & 34.61 & 33.79 & 35.51 & 0 & \\
\hline$T\left({ }^{\circ} \mathrm{C}\right)$ & 8.7 & 3.2 & 4.1 & -1.0 & 17.1 & 0 & \\
\hline Initial conditions $(\mathrm{Sv})$ & $19.1 \pm 0.8$ & $-13.6 \pm 0.7$ & $-3.9 \pm 0.5$ & $1.2 \pm 0.1$ & $-2.0 \pm 0.2$ & $106 \pm 12 \mathrm{mSv}$ & $-252 \pm 49 \mathrm{TW}$ \\
\hline Mean solution $(\mathrm{Sv})$ & $18.6 \pm 0.7$ & $-13.9 \pm 0.6$ & $-3.9 \pm 0.6$ & $1.2 \pm 0.3$ & $-2.1 \pm 0.3$ & $108 \pm 10 \mathrm{mSv}$ & $-250 \pm 12 \mathrm{TW}$ \\
\hline
\end{tabular}


a) Precipitation-Evaporation

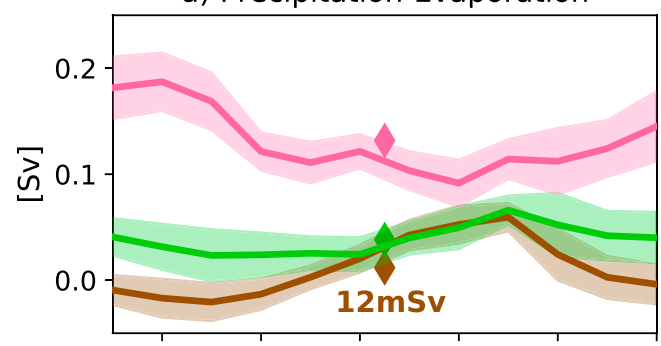

c) Iceberg melt and Runoff

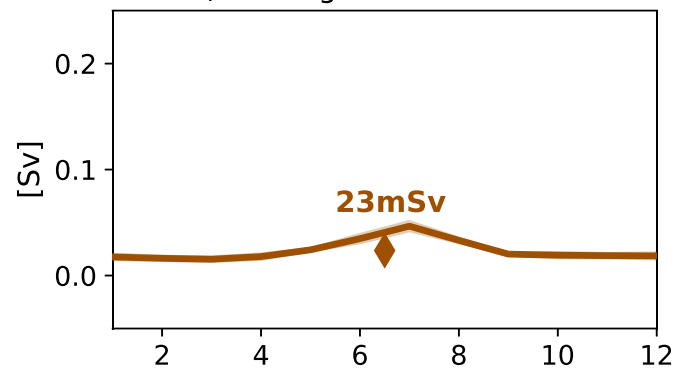

b) Sea ice

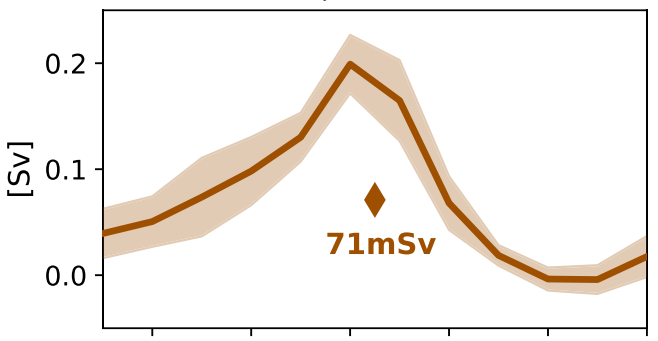

d) Heat flux

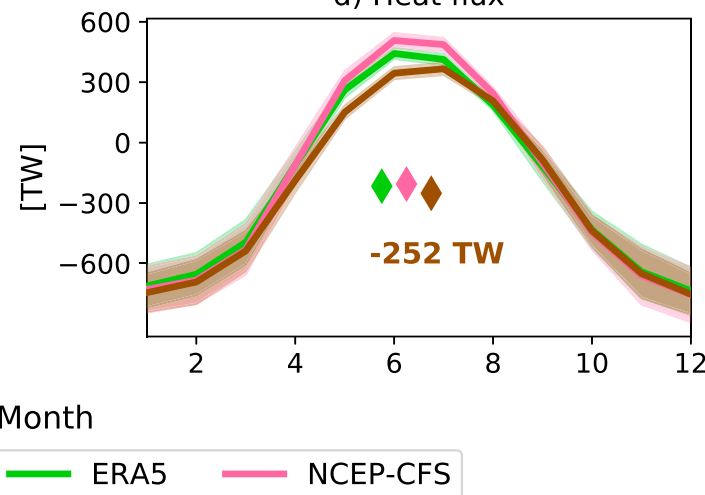

FIG. 5. Reanalysis based seasonal estimates of freshwater sources and heat flux (January 2000-December 2018). Shading shows \pm 1 standard deviation, and diamonds indicate the mean. JRA55-do/NorESM mean values are reported in brown font in each panel. The sign convention is relative to the study volume: positive indicates a net flow of freshwater into the domain, and negative heat flux means a removal of heat from the domain.

Greenland tidewater glaciers, and about half of all icebergs are thought to melt within these glacial fjords (Moon et al. 2018). The NORESM product does not account for icebergs that may drift further afield before melting (e.g., Marson et al. 2018), but our results are not sensitive to this as total iceberg melt accounts for 6 $\mathrm{mSv}$ of the total $106 \mathrm{mSv}$ of surface freshwater entering our domain (Table 1).

\section{c. Heat flux}

Heat flux $Q$ is the final component of our budget. We use the JRA55-do/NorESM net heat flux, $-252 \pm 49 \mathrm{TW}$, as our inverse model initial condition. The JRA55-do heat flux estimate agrees well with the other reanalysis products outside the summer months (Fig. 5d). The differences in summer are likely due to the presence or absence of sea ice, which modulates the atmosphereocean heat flux by reflecting solar radiation. Where there is sea ice, the JRA55-do/NorESM heat flux reported here is at the sea ice-ocean interface, whereas the other reanalysis products report a heat flux at the sea ice-atmosphere interface. Hence the JRA55do/NorESM heat flux is more consistent with our budget, which only includes sea ice as it melts into the oceanic domain. We consider an inverse model run with solid sea ice in the appendix.

\section{Inverse model results}

In the observed initial conditions described in section 4 , there is a small excess of volume, salt, and heat entering the domain: the budgets are $0.9,0.9$, and $1.1 \mathrm{~Sv}$ out of balance, respectively (after normalizing so that they have the same units using the row weighting described in section $3 b$ ). These imbalances are not significant given the uncertainties (Table 1), but in order to partition the circulation into its components meaningfully, the budgets must close exactly.

The primary difference between the initial conditions and the inverse model solution is that the inflowing AWS transport decreases from 19.1 to $18.6 \mathrm{~Sv}$ (Table 1 and Fig. 6). The decrease in AWS transport counters the excesses of volume, salinity, and heat in the initial conditions. The heat flux magnitude also decreases from -252 to $-250 \mathrm{TW}$, the inflowing SFW increases from 106 to $108 \mathrm{mSv}$, and the amount of outflowing DWS increases from 13.6 to $13.9 \mathrm{~Sv}$.

The AWS transport is adjusted by the inverse model because it is a warm, salty water mass with a large standard error, and the standard error is used to weight the inverse model unknowns. The budgets could also be closed by changes in AWN or PWN, which have more extreme representative temperatures and salinities than AWS, but their standard errors are smaller (Table 1). Changes in PWS and DWS transports are less effective in balancing the budgets because their temperatures and salinities lie between the warm, salty Atlantic Water masses and the cold, fresh PWN (Fig. 4).

Because the inverse model solution satisfies the budget conditions, we can partition the two inflowing sources of freshening, SFW and PWN, between the estuarine and overturning 

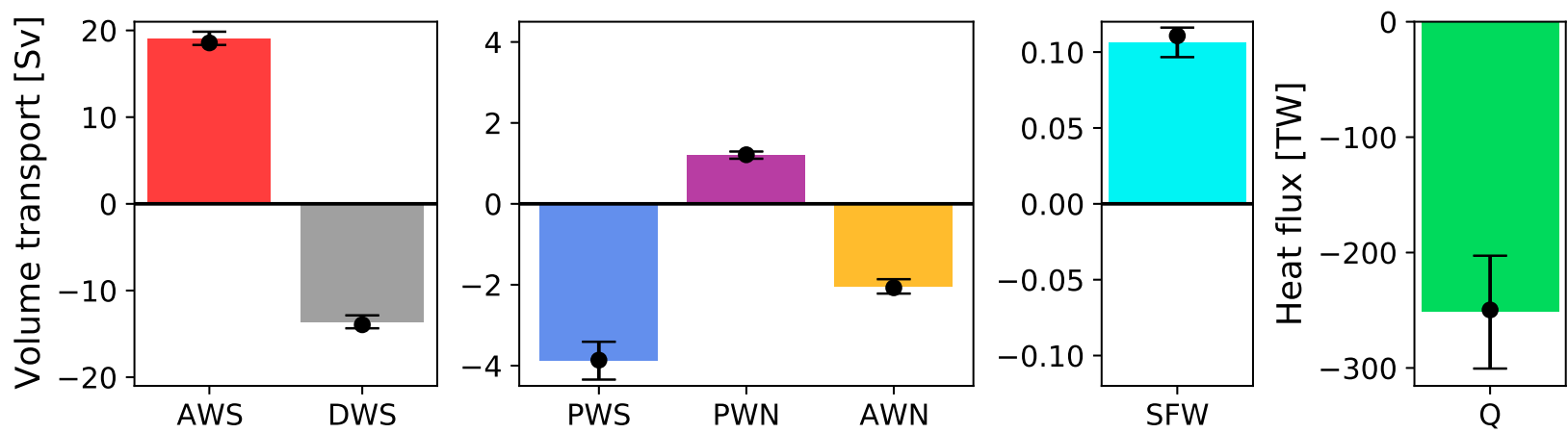

FIG. 6. Closed steady-state budget from observations. Bars are the inverse model initial conditions for each unknown: each water mass, surface freshwater (SFW), and heat flux $(Q)$. SFW includes precipitation - evaporation, runoff, iceberg melt, and sea ice melt. Error bars show \pm the column weighting applied to each unknown, which is the standard error in each estimate. Black points indicate the inverse model solution. The initial condition and solution values are listed in Table 1.

components of the circulation. As stated in section $3 \mathrm{c}$, we assume that PWN does not participate in the Atlantic Water throughflow. As the net AWN water mass is saltier than the inflowing AWS, we find that $9 \mathrm{mSv}$ of SFW evaporates from the AW throughflow (Fig. 2). This evaporation may be thought of as freshwater which enters outside of the domain and flows southward in the AW throughflow component, to account for Arctic transformations of Atlantic Waters: we discuss this further in section 6. This leaves $117 \mathrm{mSv}$ of SFW that participates in the overturning and estuarine components of the circulation.

In both the overturning and estuarine circulations, salty inflowing AWS can be freshened by both SFW and PWN. The dependence between their participation in each circulation component is given by Eqs. (5) and (6). If all the PWN stays in the estuarine circulation and becomes PWS $(\epsilon=0)$, for example, then an additional $24 \mathrm{mSv}$ of SFW is required to balance the salt budget of the estuarine circulation and the remaining $93 \mathrm{mSv}$ of SFW would freshen the overturning circulation (circles, Fig. 7). At the opposite extreme, if all PWN is mixed into the overturning circulation and becomes DWS $(\epsilon=1)$, then an additional $38 \mathrm{mSv}$ of SFW would be required to balance the salt budget of the overturning circulation, while the remaining $78 \mathrm{mSv}$ of SFW would freshen the estuarine circulation (squares, Fig. 7). Between these extremes, SFW and PWN are split more evenly between the overturning and estuarine circulations.

We can further constrain the relevant parameter space by examining the spatial distribution of the SFW sources (Fig. 8). In JRA55-do/NorESM, $52 \mathrm{mSv}$ of the total $105 \mathrm{mSv}$ of SFW enters the domain on the continental slope east of Greenland, which is associated with the estuarine circulation (Fig. 8). Suppose that $49 \%$ of the SFW ( $54 \mathrm{mSv}$ of the total $108 \mathrm{mSv}$ in the inverse model solution) enters the estuarine circulation (Fig. 2). Then $0.6 \mathrm{~Sv}$ of the total 1.2 Sv of PWN must participate in the estuarine circulation to close the salinity budget of the estuarine circulation (star, Fig. 7a). This leaves $65 \mathrm{mSv}$ of SFW and $0.6 \mathrm{~Sv}$ of PWN that participate in the overturning circulation (star, Fig. 7b). Hence, our budgets imply that about half of the PWN that enters the domain stays along the coast of Greenland and participates in the estuarine circulation, while the other half is stirred into the interior and transformed in the overturning circulation.
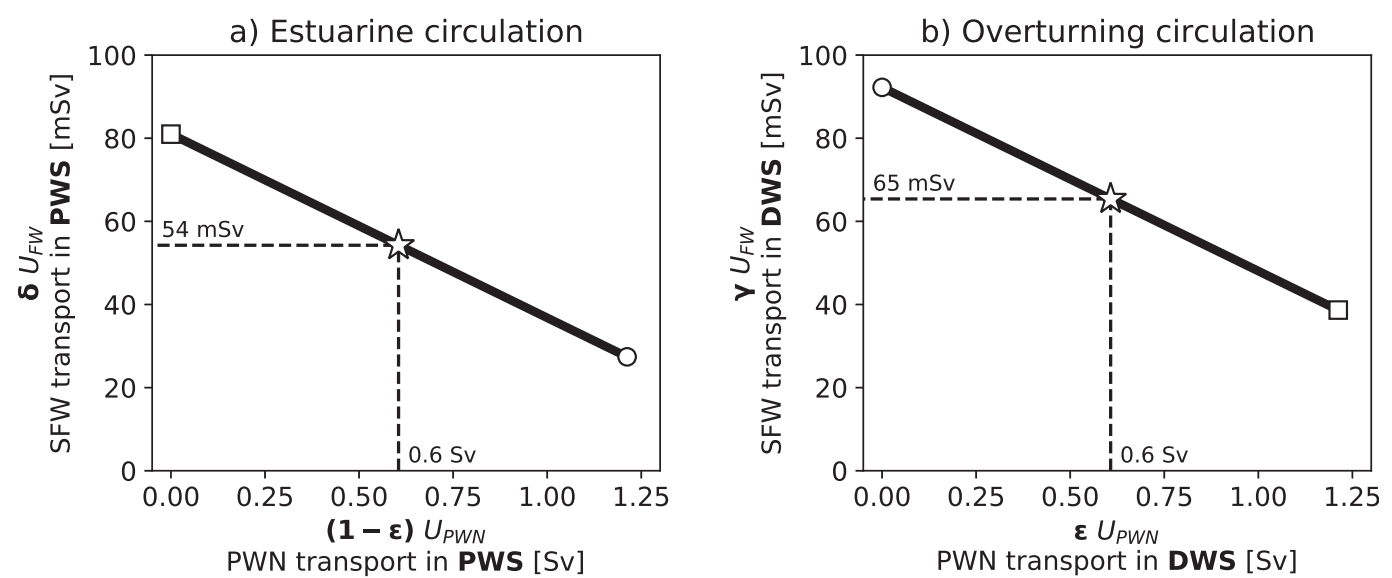

FIG. 7. Surface freshwater contributions to the (a) estuarine and (b) overturning circulations as a function of the amount of PWN that participates in each component. Circles indicate the solution in which all PWN flows into the estuarine circulation, squares indicate the solution in which all PWN flows into the overturning circulation and stars indicate the best guess solution with the SFW partitioned as in Fig. 8. 
Precipitation - Evaporation
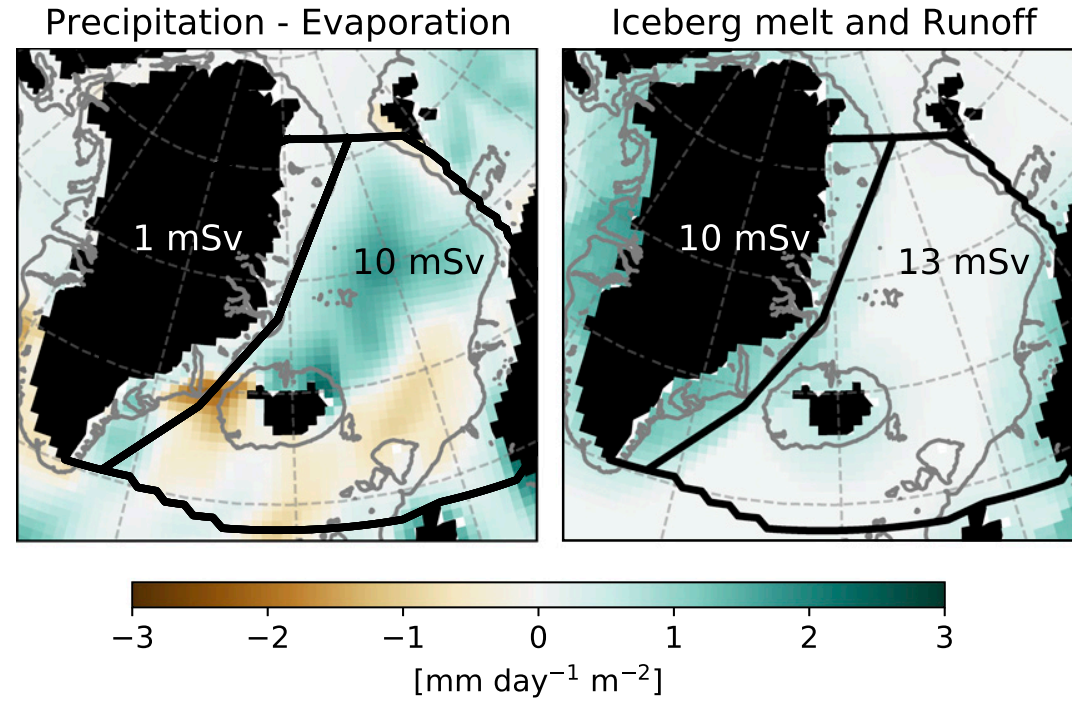

\section{Sea ice melt and freeze}
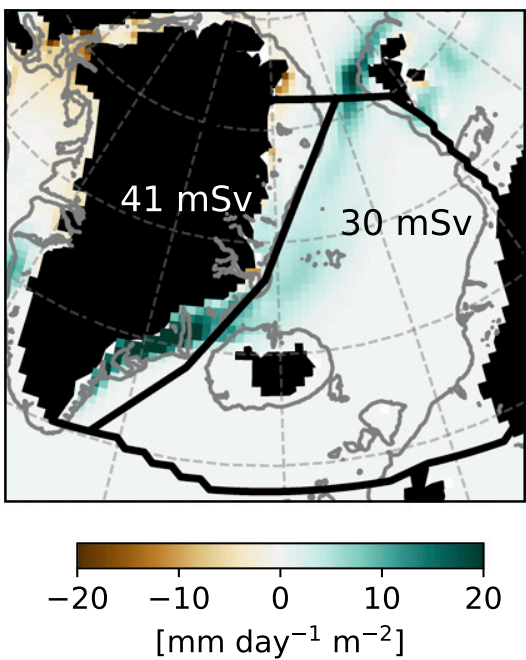

FIG. 8. Distribution of surface freshwater sources in the JRA55-do/NorESM product (2000-18). The budget volume is split into western and eastern regions (black lines) which relate to the estuarine and overturning components of the circulation, respectively. The mean sum of each source in the western (white) and eastern (black) regions are labeled in each panel. The 400-m isobath is shown in gray. Note the distinct color bar ranges.

This partitioning of PWN between the estuarine and overturning components is consistent with the water mass distribution and flow on the western shelf and slope of Fram Strait. In the Tsubouchi et al. (2019) product, 0.6 Sv of the southward PWN flow in Fram Strait is inshore of $5^{\circ} \mathrm{W}$, on the shelfbreak (Fig. 3). Hence, our analysis suggests that the majority of PWN on the shelf at Fram Strait remains on the shelf as it flows southward along the Greenland coast. As this Polar Water travels southward in the estuarine circulation, it is mixed with about $54 \mathrm{mSv}$ of freshwater from sea ice melt, iceberg melt, and runoff as well as about 3.2 Sv Atlantic Water (Fig. 2). Polar Water on the continental slope of Fram Strait is more likely to be stirred into the interior, where it will mix with 13.3 Sv of Atlantic Water and 65 $\mathrm{mSv}$ of sea ice melt and precipitation, and be vigorously cooled by heat fluxes into the deep limb of the overturning circulation.

\section{Discussion}

In this study, we presented steady-state budgets of volume, heat, and salt for the Nordic and eastern subpolar Seas. We used new observations from the Overturning in the Subpolar North Atlantic Program (OSNAP) East at approximately $60^{\circ} \mathrm{N}$ (Lozier et al. 2019), an ocean observation based product from Fram Strait and the Barents Sea Opening (Tsubouchi et al. 2019), atmospheric reanalyses (Tsujino et al. 2018), and simulations from the Norwegian Earth System Model (Bentsen et al. 2019) to constrain these budgets, and have avoided using ambiguous reference salinities entirely (Schauer and Losch 2019). Our budgets were split into a simple set of water masses reflecting the overturning and estuarine circulations (Fig. 2) with the aim of quantifying how much freshwater participates in each circulation component.

Using initial conditions based on observations, we closed budgets of volume, salt, and heat using an inverse model framework (Table 1). We found that at the southern boundary of the domain (OSNAP East), 18.6 Sv of warm and salty Atlantic Water (AWS) flows northward and is transformed to 13.9 Sv of cooled and freshened outflowing Deep Water (DWS; overturning circulation) and 3.9 Sv of Polar Water (PWS; estuarine circulation). This transformation requires a heat loss of $250 \mathrm{TW}$ and an addition of $108 \mathrm{mSv}$ of surface freshwater over the domain. At the northern boundary (Fram Strait and the Barents Sea Opening) there is an outflow of $2.1 \mathrm{~Sv}$ Atlantic Water (AWN; AW throughflow), and an inflow of 1.2 Sv cold, fresh Polar Water (PWN).

Based on the geographical distribution of flow features associated with the overturning and estuarine circulations, we estimated that surface freshwater fluxes are roughly evenly split between the two components (Fig. 8). In order for the volume and salt budgets to be consistent with this split, we found that about half of the inflowing PWN participates in the overturning circulation, and the other half in the estuarine circulation (Fig. 2).

Our result that a significant amount of Polar Water is diverted into the interior of the Nordic Seas is broadly consistent with the few existing observations from this region. Foukal et al. (2020) use ice-mounted buoys to support their finding that waters on the shelf at Fram Strait flow southward along the full coast of eastern Greenland, while those on the slope are likely to be stirred into the interior. Håvik et al. (2017) describe the evolution of the circulation from Fram Strait to Denmark Strait and find a reduction in freshwater transport as the East Greenland shelfbreak current travels southward, and identify two outer limbs of the East Greenland Current system that are stirred into the Nordic Seas interior. Both observation- and model-based studies find that there is less stirring of Polar Waters into the interior from Denmark Strait to Cape Farewell (Le Bras et al. 2018; Pennelly et al. 
2019). The amount of Polar Water that we estimate participates in the overturning circulation is also consistent with the transport of Polar Water offshore of the shelfbreak in Fram Strait (section 5).

Our estimate of the present-day sources of freshening in the overturning circulation is a critical first step to diagnosing how the North Atlantic-Arctic circulation may change as freshwater fluxes increase in the future. We estimate that a significant portion of the fresh Polar Waters flowing southward through Fram Strait are stirred into the overturning circulation's lower limb, so that changes in Polar Water properties are likely to impact the overturning circulation. Because of their geographical distribution, we suggest that icebergs and runoff from the Greenland ice sheet are more likely to participate in the estuarine circulation, whereas precipitation changes may impact the overturning circulation. This is consistent with modeling studies, which find little impact of Greenland melt on the overturning circulation (Lenaerts et al. 2015; Böning et al. 2016; Dukhovskoy et al. 2016). The impacts of river runoff from Iceland and Norway, which only amount to about $6 \mathrm{mSv}$ combined, are less clear because of their proximity to the Atlantic Water throughflow.

Our water mass framework was constructed to separate fresh boundary currents from the overturning circulation. To close the volume budget we also included an Atlantic Water throughflow component, which accounts for the net northward flux of waters east of Greenland and transformations in the Barents and Arctic Seas that do not fit into the estuarineoverturning circulation paradigm (Fig. 3). The interpretation of this component is therefore somewhat counterintuitive; the net volume transport is much smaller than the northward and southward flows, which makes the "net" temperature and salinity artificially high. The fact that our AWN water mass is warmer and saltier than the inflowing AWS does not mean that the Atlantic Waters flowing northward get warmer and saltier along the way, but is an artifact which stems from our imperfect water mass framework. By the same token, the fact that we require $9 \mathrm{mSv}$ of evaporation from this circulation component likely indicates freshening of deep waters to the north of our domain. This transformation is much smaller than the overturning and estuarine transformations that are our focus but warrants future study.

Statistical uncertainties are accounted for in our inverse model framework, but there are significant uncertainties in both the ocean observations and reanalysis products that are not accounted for. We explore the impact of two key uncertainties, the Polar Water salinity and the amount of surface freshwater flux, in the appendix. Note that these sensitivity tests are not predictive, as our model includes no dynamical constraints, but rather illustrate how our steady-state inverse results are sensitive to these uncertainties. Our result that a significant portion of Fram Strait Polar Waters participates in the overturning circulation is robust throughout these sensitivity tests (stars in Fig. A1b).

Our estimate of how the budget is split into circulation components is based on the geographic distribution of surface freshwater fluxes, which is also relatively uncertain. Though JRA55-do is implemented widely in ocean-sea ice models, its uncertainties are unknown, particularly in the NorESM sea ice model implementation. If in reality more sea ice is advected into the Nordic Seas interior, for example, less Polar Water would be required to participate in the overturning circulation. Furthermore, we do not account for the possibility that surface freshwater fluxes may be stirred across the boundaries we define. Our analysis is meant as a best guess given the current observations, and our framework will remain a useful means of interpretation as observations improve.

Particularly because the ocean observations we used as the starting point for our budget are not contemporaneous, we investigated the impact of interannual variability on our steady-state budget solution using the NorESM climate model (appendix). We found that, while noncontemporaneous observations at the northern and southern boundaries can result in significant errors, the length of the observational records is more important in approximating the steady-state, as the timemean is better approximated by a longer record.

Recent studies have reported water mass property changes that would impact the Deep Water and Atlantic Water components of our budget (Brakstad et al. 2019; Holliday et al. 2020; Tsubouchi et al. 2020). The variability they report is within the range considered in the NorESM model analysis, so we do not expect that it would impact the overall steady-state closure. In future work we intend to expand this framework to account for water mass property variations and include storage terms explicitly. Another important future step is investigating the dynamics that underlie the freshwater pathways we have identified.

The uncertainties in high-latitude observations, particularly with regards to freshwater, complicate model-observation comparisons. We have presented a self-consistent framework for diagnosing the pathways of oceanic and surface freshwater sources from observations, which we hope will provide a means to ground-truth models and increase confidence in their predictions.

Acknowledgments. We gratefully acknowledge the U.S. National Science Foundation: this work was supported by Grants OCE-1258823, OCE-1756272, OCE-1948335, and OCE-2038481. L.H.S. thanks the U.S. Norway Fulbright Foundation for the Norwegian Arctic Chair Grant 2019-20 that made the visit to Scripps Institution of Oceanography possible. N.P.H. acknowledges support by the U.K. Natural Environment Research Council (NERC) National Capability program CLASS (NE/R015953/1), and Grants U.K.-OSNAP (NE/K010875/1, NE/K010875/2) and U.K.-OSNAP Decade (NE/T00858X/1). We acknowledge the World Climate Research Programme, which, through its Working Group on Coupled Modelling, coordinated and promoted CMIP6. We thank the NorESM Consortium for producing and making available their model output, the ESGF for archiving the data and providing access, and the multiple funding agencies who support CMIP6 and ESGF. We gratefully acknowledge the many scientists and mariners who went to sea to collect the observational data, without whom this study would not be possible.

Data availability statement. OSNAP data were collected and made freely available by the OSNAP (Overturning in the 
a) Estuarine circulation

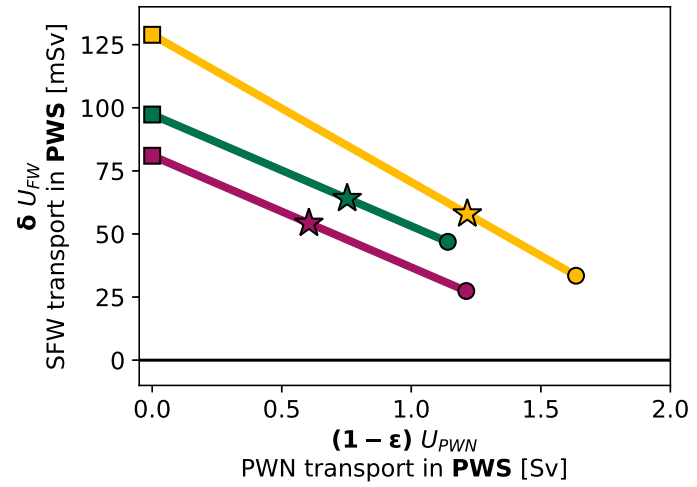

b) Overturning circulation

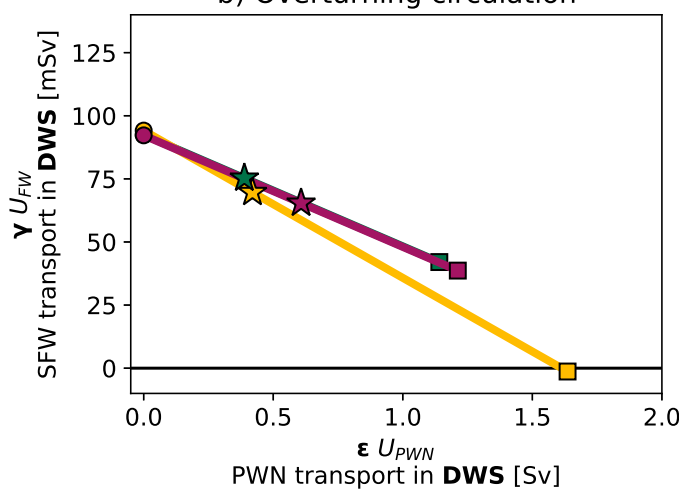

Base case Polar Waters fresher by 0.5

Add $20 \mathrm{mSv}$ of Surface Fresh Water

FIG. A1. Surface freshwater contributions to the (a) estuarine and (b) overturning components of the circulation as a function of the amount of PWN that participates in each. The magenta line shows the partitioning of SFW and PWN for the base case (repeated from Fig. 7), the yellow line shows this partitioning for the case in which both Polar Waters are 0.5 fresher, and the green line shows the solution when $20 \mathrm{mSv}$ of freshwater are added to the budget. Circles highlight the solutions in which all PWN flows into the estuarine circulation, squares indicate the solutions in which all PWN flows into the overturning circulation, and stars indicate the best guess solutions with the SFW partitioned as in Fig. 8. Note that in each case, a different amount of SFW participates in the AW throughflow.

Subpolar North Atlantic Program) and all the national programs that contribute to it. All OSNAP data products are available at www.o-snap.org (https://doi.org/10.35090/wa93m688). The Fram Strait and Barents Sea Opening Tsubouchi et al. (2019) dataset can be accessed at https://doi.pangaea.de/ 10.1594/PANGAEA.909966.

Most reanalysis data was downloaded from the Research Data Archive (RDA): https://rda.ucar.edu. JRA55-do was accessed on 5 April 2020 (JMA 2013). NCEP CFS was accessed on 2 April 2020 (Saha et al. 2010a). NCEP CFSv2 was accessed on 7 February 2020 (Saha et al. 2012). ERA5 was accessed on 2 April 2020 from the Copernicus Climate Change Service (C3S) Climate Data Store: https://cds.climate.copernicus.eu (Copernicus Climate Change Service 2017).

Monthly fields from the NorESM2-LM (Bentsen et al., 2019) have been provided through the Ocean Model Intercomparison Project Phase 2 (OMIP2) experiment as part of the Coupled Model Intercomparison Project Phase 6 (CMIP6), and are available for download on the Earth System Grid Federation (ESGF) website: https://esgf-node.llnl.gov/ search/cmip6/. An extracted set of the NorESM simulations is made available on the Bjerknes Climate Data Center (https:// www.bcdc.no/).

\section{APPENDIX}

\section{Inverse Model Uncertainty and Sensitivity}

Here we explore additional uncertainties that are outside of the primary focus of the study. In sections a, b, and c, we provide examples of budget sensitivities to the primary uncertainties and illustrate the detailed mechanics of the inverse model. The partitioning of Polar Water and surface freshwater fluxes (SFW) between circulation components in these examples is shown in Fig. A1. In section d, we examine the uncertainty due to interannual variability based on a NorESM model analysis.

\section{a. Uncertainty due to polar water salinity}

In our inverse model framework, we assume that each water mass has a constant salinity and temperature that is well represented by the mean fields. The PWN and PWS are the most uncertain of all inflowing and outflowing water masses. This is because mooring instruments cannot be placed near the surface in these ice-riddled regions and do not measure the salinity stratified near-surface layer (de Steur et al. 2014; Le Bras et al. 2018). These Polar Water salinities are central to our interpretation of how freshwater moves through the system, so we consider how this uncertainty impacts the budget by evaluating the inverse model solution for a range of PWS and PWN salinities. We use the inverse model solution as the initial condition in each case, and the column weights of each water mass are set to $1 \mathrm{~Sv}$.

When the PWN salinity is reduced with the PWS salinity held constant (Fig. A2a), the most significant water mass adjustment is a reduction of the inflowing PWN transport. This is compensated by an additional transport of all saltier water masses: AWS, AWN, and DWS. In other words, as PWN is made fresher, the budget adjusts by replacing PWN inflow with saltier AWS inflow, and by producing less of the saltier DWS and AWN. SFW also decreases to balance the salt budget, and the heat flux decreases (more heat is extracted) to counter the fact that cold PWN has been replaced by warmer water masses.

When the PWS salinity is reduced with PWN salinity held constant (Fig. A2b), the response is almost exactly the opposite of the response to freshening PWN, but the adjustments are 
a) Vary PWN salinity

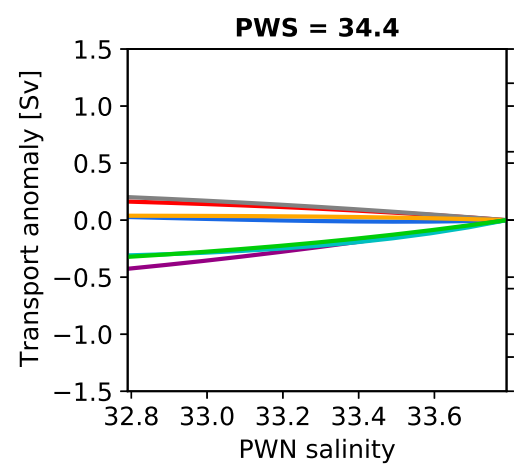

b) Vary PWS salinity

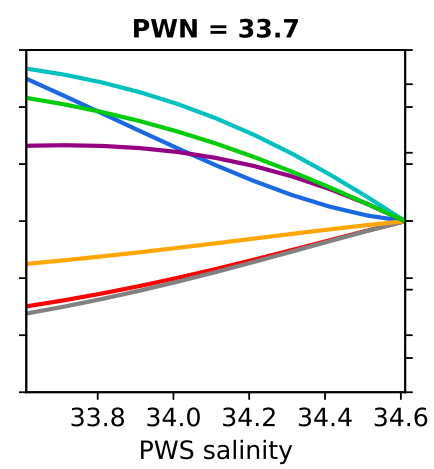

c) Vary both PW salinities

PWN salinity $\begin{array}{llllll}32.8 & 33.0 & 33.2 & 33.4 & 33.6\end{array}$

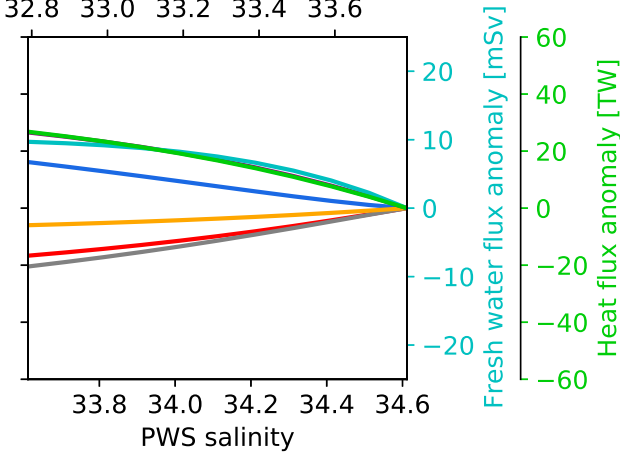

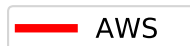

PWS

DWS

AWN

PWN

FIG. A2. Steady-state inverse model solution sensitivity to Polar Water salinities. Water mass transport anomalies, color-coded as in the legend, are scaled as in the leftmost $y$ axis. Freshwater transport and heat flux anomalies are color-coded and scaled as in the right $y$ axes. Anomalies are taken from the inverse model solutions shown in Fig. 6 and Table 1. (a) Sensitivity to changing PWN salinity, with PWS salinity held constant. (b) Sensitivity to changing PWS salinity, with PWN held constant. (c) Sensitivity to changing both PWN and PWS by the same amount.

larger because PWS has a larger steady-state transport than PWN. In this case, the most significant water mass adjustment is a positive transport anomaly in PWS, or a weaker outflow of PWS. This is accompanied by an increase in PWN inflow, and a decrease in transport of the saltier water masses. So, if PWS salinity is reduced while PWN salinity is held constant, the system adjusts by increasing the inflow of the fresh PWN, decreasing the inflow of salty AWS, producing less fresh PWS, and producing more relatively salty DWS and AWN. Additionally, SFW is added and there is a positive heat flux anomaly: less heat needs to be removed from the system as warm AWS and AWN are replaced by cold PWN. When both

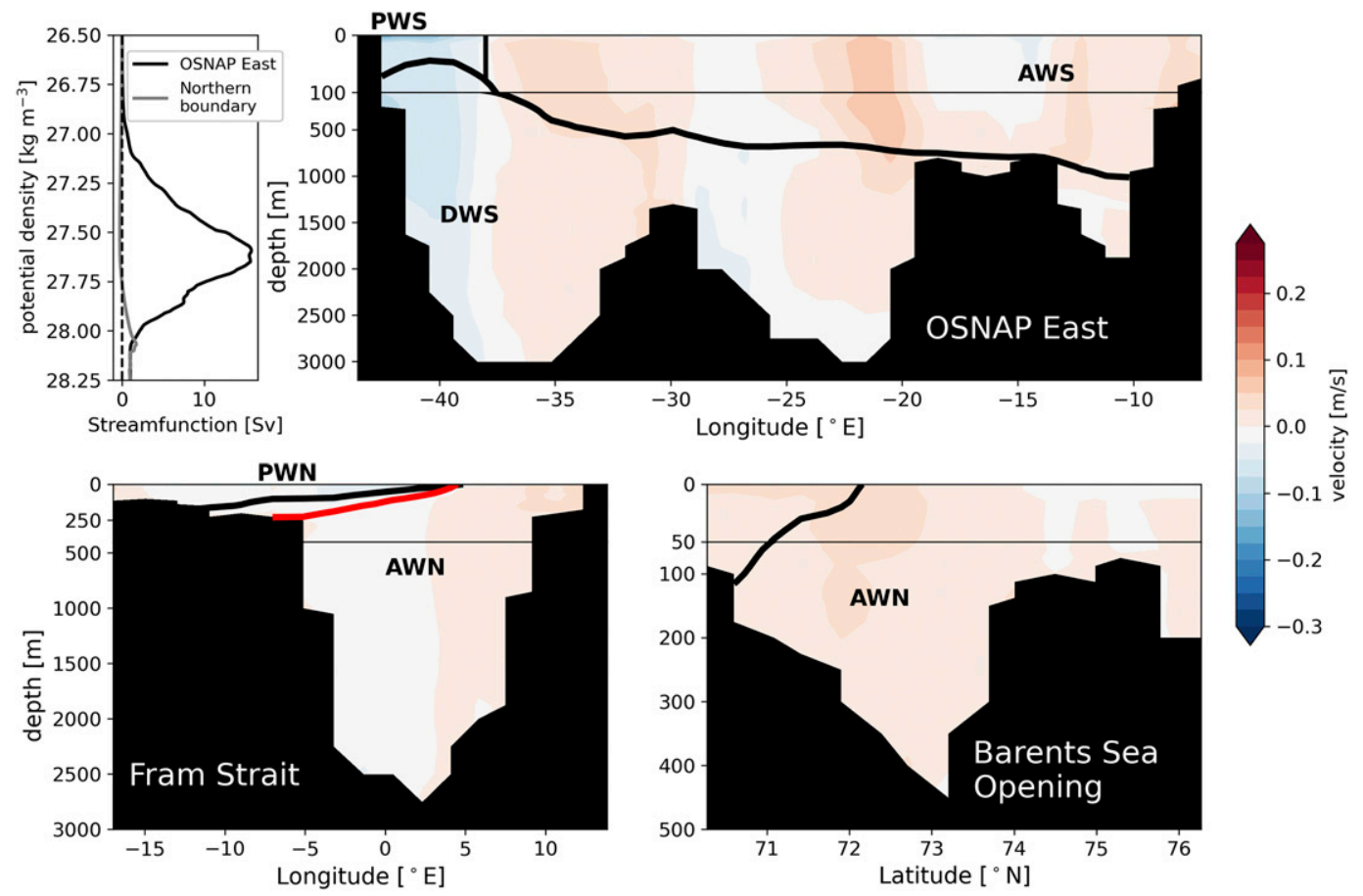

FIG. A3. NorESM 19-yr mean streamfunctions and cross-track velocity fields shown as in Fig. 3. Note that the isopycnal of maximum overturning (black lines) is $\sigma_{\theta}=27.58 \mathrm{~kg} \mathrm{~m}^{-3}$, and that AWS and PWS are separated at $38^{\circ} \mathrm{W}$. 

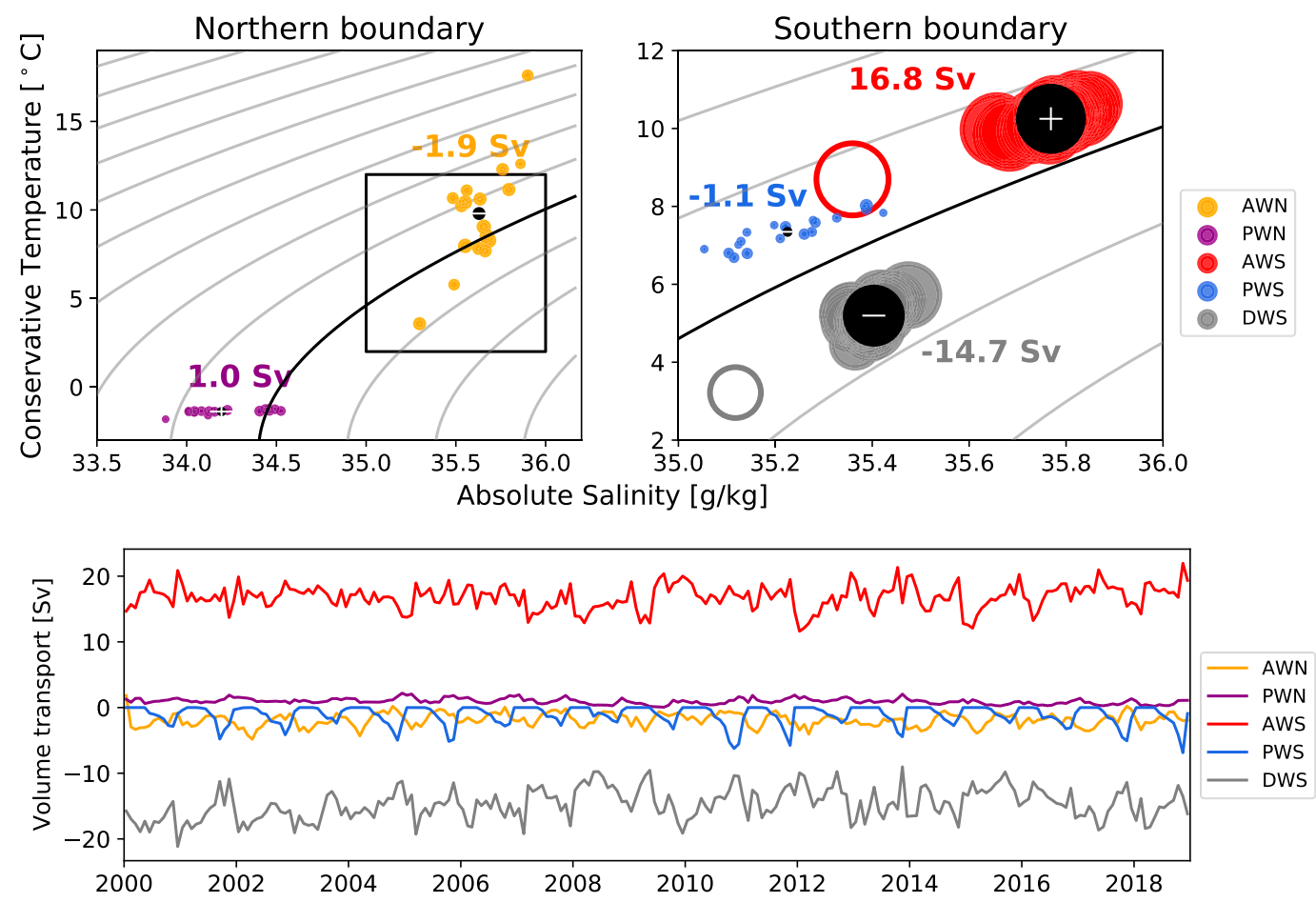

FIG. A4. (top) NorESM transport-weighted water mass properties, presented as in Fig. 4. Black dots represent 19-yr averages (2000-18), and colorful dots are annual means. The black box in the left panel indicates the axis range of the right panel. The red and gray empty circles show the observational annual mean AWS and DWS properties for comparison. (bottom) NorESM water mass transport time series.

Polar Water masses are freshened by the same amount (Fig. A2c), the response resembles the sensitivity to freshening PWS, as PWS has a larger transport than PWN.

The relative sensitivities of the inverse model unknowns are dependent on the column-weighting value chosen, hence our choice of equal $1 \mathrm{~Sv}$ weighting for each water mass in this sensitivity test. Because of the difference in their magnitudes, however, we cannot use the water mass transport weighting for the freshwater flux or heat flux; instead we use $20 \%$ of their initial value. If we instead choose a $0.1-\mathrm{Sv}$ column weighting for each water mass, freshwater transport is a more available lever in the inverse model relative to water mass transports. Using $0.1 \mathrm{~Sv}$ for the oceanic water mass weights in the case in which both PWN and PWS are fresher by 0.5 , SFW would increase by $34 \mathrm{mSv}$ (relative to $7 \mathrm{mSv}$ for $1-\mathrm{Sv}$ water mass weights), whereas all water mass transports respond by less than $0.03 \mathrm{~Sv}$, and the heat flux changes by less than 3 TW. In other words, the column weighting significantly affects the inverse model solution.

\section{b. Uncertainty due to surface freshwater fluxes}

The surface freshwater flux initial condition is based on the JRA55-do reanalysis product and its implementation in the NorESM model (section 4b). This SFW value could be an underestimate as there is higher net precipitation minus evaporation in the two other reanalysis products. To test how the steady-state budgets could close for a larger freshwater input, we add $20 \mathrm{mSv}$ of freshwater to our inverse model solution, so that the total freshwater flux is $128 \mathrm{mSv}$. As for our test of sensitivity to the Polar Water salinity, the initial conditions are set to the inverse model solution otherwise. The column weights are set to $1 \mathrm{~Sv}$ per water mass, $20 \%$ of its initial value for the heat flux, and to $10^{-10} \mathrm{~Sv}$ for the SFW, so that it is not adjusted.

In order for the salt budget to close with $20 \mathrm{mSv}$ of additional freshwater, the AWS inflow is increased by $0.8 \mathrm{~Sv}$ and the PWN inflow is decreased by $0.8 \mathrm{~Sv}$ as additional salt is required (Fig. A1). Due to the additional inflow of warm AWS, an additional 19 TW must be extracted to balance the heat budget. This example illustrates the significant impact that the freshwater flux can have on budget closure despite its relatively small transport.

\section{c. Considering solid sea ice in the budget}

To estimate how considering solid sea ice would impact the budget, we add sea ice volume transport to the inverse model as an unknown. We assume a sea ice salinity of $6 \mathrm{~g} \mathrm{~kg}^{-1}$ and a temperature of $-30^{\circ} \mathrm{C}$, which implies that about one-third of the heat for melting sea ice comes from the ocean (e.g., Jenkins 1999). As in the PW salinity tests, the column weights are set to $1 \mathrm{~Sv}$ per water mass and $20 \%$ of their initial value for the surface freshwater flux, sea ice flux, and heat flux. The budget is closed by increasing the sea ice volume transport by $2 \mathrm{mSv}$, increasing the PWN inflow by $0.2 \mathrm{~Sv}$, and decreasing the AWS and DWS transports by about $0.15 \mathrm{~Sv}$ each. The heat flux increases by $15 \mathrm{TW}$ : about $10 \mathrm{TW}$ of this heat is extracted from 
the ocean to melt the sea ice, while the rest compensates for water mass changes related to the sea ice salinity of 6. Overall, the budget is relatively unchanged by considering solid sea ice separately.

\section{d. Uncertainty due to interannual variability}

To assess the impact of interannual variability on our budget results, we analyzed monthly mean NorESM climate model fields from January 2000 to December 2018. This is particularly relevant because our steady-state budget analysis does not include storage terms and the observations at the northern and southern boundaries of our domain are not contemporaneous.

The transport-weighted water masses in NorESM are defined as described for the observations in section 4 , but we identify a different isopycnal of maximum overturning at OSNAP East in the model $\left(\sigma_{\theta}=27.58 \mathrm{~kg} \mathrm{~m}^{-3}\right)$ and we use $38^{\circ} \mathrm{W}$ as the boundary between AWS and PWS (Fig. A3). We also consider all waters on the shelf of Greenland at OSNAP East to be PWS (some are denser than the isopycnal of maximum overturning in NorESM). The water mass properties in NorESM are warmer and saltier than in the observations, but show similar relationships to one another (Fig. A4). Our intention is not to directly compare the model and observations, but to use the model to gain insight into how interannual variability and storage may manifest in our steady-state inverse model framework.

First, we diagnose the steady-state budgets in NorESM by running the inverse model using the 19-yr mean water mass properties and transports (Fig. A4), SFW, and $Q$ as initial conditions. Note that the $19-\mathrm{yr}$ mean SFW and $Q$ are also the initial conditions in our observation-based budgets (Table 1). The differences between the NorESM 19-yr mean initial conditions and inverse model solutions are due to submonthly eddy fluxes.

Next, we run the inverse model using sequential 4-yr means as the initial conditions to approximately match the length of our observational records (45 months at the southern boundary and 68 months at the southern boundary). To test how the fact that our observations are not contemporaneous may impact our results, we also run the inverse model using offset 4-yr mean initial conditions at the northern and southern boundaries.

Finally, we test how the length of the time series impacts how representative they are of the steady-state solution, we run the inverse model using each of the 19 one-year means as initial conditions. As for the 4-yr means, we run the model using both contemporaneous and offset 1-yr means.

To quantify how our 1- and 4-yr mean inverse model results differ from the full 19-yr mean solution, we calculate the mean absolute percent error for the inverse model solutions, that is the mean of the absolute value of the percent error for each component of the model solution (the five water mass transports, SFW, and $Q$ ). We also show the mean absolute percent error for the salinity and temperature transports as the water mass salinities and temperatures change with time. The salinity and temperature transports are normalized by $35 \mathrm{~g} \mathrm{~kg}^{-1}$ and $10^{\circ} \mathrm{C}$ as they are for the inverse model weighting.

Overall, we find that the inverse model solutions based on 4-yr means have lower percent error than the solutions based
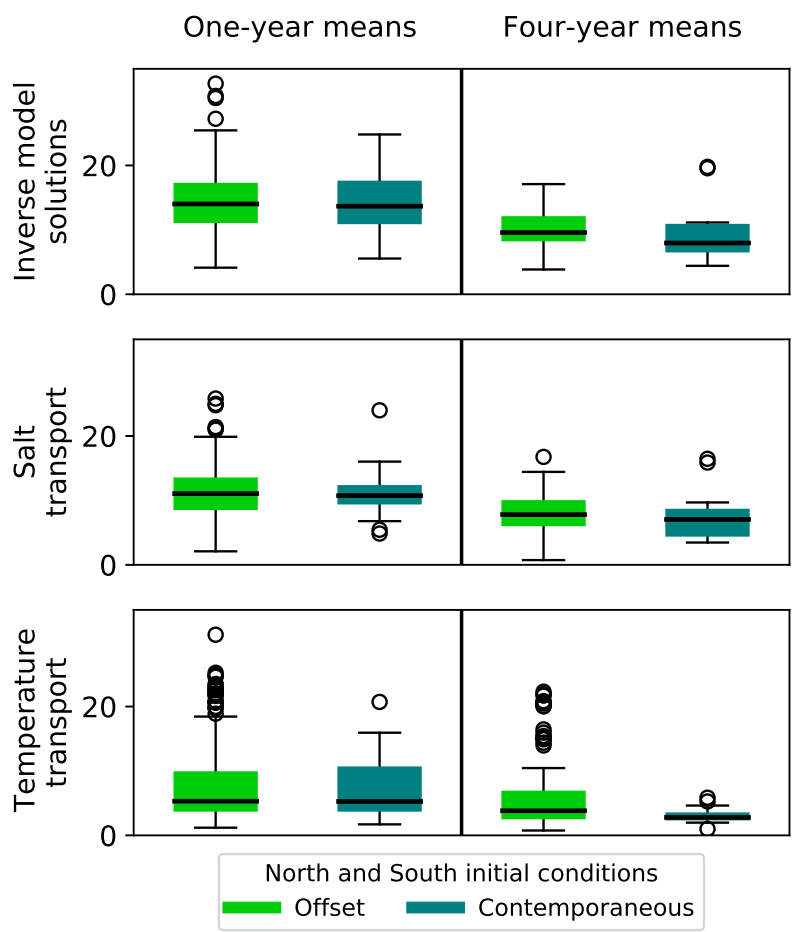

FIG. A5. The mean absolute percent error from the NorESM 19yr mean solution for inverse model runs using (left) 1-yr and (right) 4-yr means as initial conditions. Light green boxes indicate cases in which the initial conditions at the northern and southern boundaries of the domain are offset in time, while teal boxes show cases in which they are contemporaneous. Boxes show the interquartile range, thick black lines show the median, whiskers show the data points that bracket 4 times the interquartile range (Tukey's definition), and circles are outliers.

on 1-yr means (Fig. A5). The difference is not as great when comparing solutions using contemporaneous versus offset initial conditions. We do find, however, that there are more outliers with high percentage error when offset initial conditions are used, particularly in temperature transport. In sum, our NorESM analysis suggests that 4-yr mean budgets will better approximate the steady-state than 1-yr mean budgets, even if the initial conditions are not contemporaneous at the northern and southern boundaries.

\section{REFERENCES}

Bacon, S., Y. Aksenov, S. Fawcett, and G. Madec, 2015: Arctic mass, freshwater and heat fluxes: Methods and modelled seasonal variability. Philos. Trans. Roy. Soc., 373A, 20140169 , https://doi.org/10.1098/rsta.2014.0169.

Bamber, J. L., A. J. Tedstone, M. D. King, I. M. Howat, E. M. Enderlin, M. R. van den Broeke, and B. Noel, 2018: Land ice freshwater budget of the Arctic and North Atlantic Oceans: 1. Data, methods, and results. J. Geophys. Res. Oceans, 123, 1827-1837, https://doi.org/10.1002/2017JC013605.

Bentsen, M., and Coauthors, 2013: The Norwegian Earth System Model, NorESM1-M - Part I: Description and basic evaluation of the physical climate. Geosci. Model Dev., 6, 687-720, https://doi.org/10.5194/gmd-6-687-2013. 
- , and Coauthors, 2019: NCC NorESM2-LM model output prepared for CMIP6 OMIP OMIP2, version 20200401. Earth System Grid Federation, accessed 1 May 2020, https://doi.org/ 10.22033/ESGF/CMIP6.8089.

Beszczynska-Möller, A., E. Fahrbach, U. Schauer, and E. Hansen, 2012: Variability in Atlantic water temperature and transport at the entrance to the Arctic Ocean, 1997-2010. ICES J. Mar. Sci., 69, 852-863, https://doi.org/10.1093/icesjms/fss056.

Boisvert, L. N., M. A. Webster, A. A. Petty, T. Markus, D. H. Bromwich, and R. I. Cullather, 2018: Intercomparison of precipitation estimates over the Arctic Ocean and its peripheral seas from reanalyses. J. Climate, 31, 8441-8462, https:// doi.org/10.1175/JCLI-D-18-0125.1.

Böning, C. W., E. Behrens, A. Biastoch, K. Getzlaff, and J. L. Bamber, 2016: Emerging impact of Greenland meltwater on deepwater formation in the North Atlantic Ocean. Nat. Geosci., 9, 523-527, https://doi.org/10.1038/ngeo2740.

Brakstad, A., K. Våge, L. Håvik, and G. W. K. Moore, 2019: Water mass transformation in the Greenland Sea during the period 1986-2016. J. Phys. Oceanogr., 49, 121-140, https://doi.org/ 10.1175/JPO-D-17-0273.1.

Budéus, G., E. Fahrbach, and P. Lemke, 2008: The expedition ARKTIS-XXI/1 a and b of the research vessel "Polarstern" in 2005. Berichte zur Polar- und Meeresforschung (Reports on Polar and Marine Research), Alfred Wegener Institute for Polar and Marine Res. 570, 145 pp., https://epic.awi.de/28681/.

Carmack, E. C., 2007: The alpha/beta ocean distinction: A perspective on freshwater fluxes, convection, nutrients and productivity in high-latitude seas. Deep-Sea Res. II, 54, 2578-2598, https://doi.org/10.1016/j.dsr2.2007.08.018.

Chafik, L., and T. Rossby, 2019: Volume, heat and freshwater divergences in the subpolar North Atlantic suggest the Nordic Seas as key to the state of the meridional overturning circulation. Geophys. Res. Lett., 46, 4799-4808, https://doi.org/ 10.1029/2019GL082110.

Compo, G. P., and Coauthors, 2011: The Twentieth Century Reanalysis Project. Quart. J. Roy. Meteor. Soc., 137, 1-28, https://doi.org/10.1002/qj.776.

Copernicus Climate Change Service, 2017: ERA5: Fifth generation of ECMWF atmospheric reanalyses of the global climate. Copernicus Climate Change Service Climate Data Store (CDS), accessed 4 May 2018, https://doi.org/10.24381/cds.f17050d7.

Dee, D. P., and Coauthors, 2011: The ERA-Interim reanalysis: Configuration and performance of the data assimilation system. Quart. J. Roy. Meteor. Soc., 137, 553-597, https://doi.org/ 10.1002/qj.828.

de Steur, L., E. Hansen, R. Gerdes, M. Karcher, E. Fahrbach, and J. Holfort, 2009: Freshwater fluxes in the East Greenland Current: A decade of observations. Geophys. Res. Lett., 36, L23611, https://doi.org/10.1029/2009GL041278.

— , and Coauthors, 2014: Impact of recirculation on the East Greenland Current in Fram Strait: Results from moored current meter measurements between 1997 and 2009. Deep-Sea Res. I, 92, 26-40, https://doi.org/10.1016/j.dsr.2014.05.018.

, R. S. Pickart, A. Macrander, K. Våge, B. Harden, S. Jónsson, S. Østerhus, and H. Valdimarsson, 2017: Liquid freshwater transport estimates from the East Greenland Current based on continuous measurements north of Denmark Strait. J. Geophys. Res. Oceans, 122, 93-109, https://doi.org/10.1002/ 2016JC012106.

Dickson, R. R., E. M. Gmitrowicz, and A. J. Watson, 1990: Deepwater renewal in the northern North Atlantic. Nature, 344, 848-850, https://doi.org/10.1038/344848a0.
Dukhovskoy, D. S., and Coauthors, 2016: Greenland freshwater pathways in the sub-Arctic Seas from model experiments with passive tracers. J. Geophys. Res. Oceans, 121, 877-907, https:// doi.org/10.1002/2015JC011290.

Eldevik, T., and J. E. Ø. Nilsen, 2013: The Arctic-Atlantic thermohaline circulation. J. Climate, 26, 8698-8705, https:// doi.org/10.1175/JCLI-D-13-00305.1.

Florindo-López, C., S. Bacon, Y. Aksenov, L. Chafik, E. Colbourne, and N. P. Holliday, 2020: Arctic Ocean and Hudson Bay freshwater exports: New estimates from seven decades of hydrographic surveys on the Labrador Shelf. J. Climate, 33, 8849-8868, https://doi.org/10.1175/JCLI-D-19-0083.1.

Foukal, N. P., R. Gelderloos, and R. S. Pickart, 2020: A continuous pathway for fresh water along the East Greenland shelf. Sci. Adv., 6, eabc4254, https://doi.org/10.1126/sciadv. abc 4254

Griffies, S. M., and Coauthors, 2016: OMIP contribution to CMIP6: Experimental and diagnostic protocol for the physical component of the Ocean Model Intercomparison Project. Geosci. Model Dev., 9, 3231-3296, https://doi.org/10.5194/gmd-9-32312016.

Hansen, B., S. Osterhus, W. R. Turrell, S. Jónsson, H. Valdimarsson, H. Hátún, and S. M. Olsen, 2008: The inflow of Atlantic water, heat, and salt to the Nordic Seas across the GreenlandScotland Ridge. Arctic-Subarctic Ocean Fluxes: Defining the Role of the Northern Seas in Climate, R. R. Dickson, J. Meincke, and P. Rhines, Eds., Springer, 15-43, https:// doi.org/10.1007/978-1-4020-6774-7.

Håvik, L., R. S. Pickart, D. J. Torres, A. M. Thurnherr, A. Beszczynska-Möller, W. Walczowki, and W.-J. von Appen, 2017: Evolution of the East Greenland Current from Fram Strait to Denmark Strait: Synoptic measurements from summer 2012. J. Geophys. Res. Oceans, 122, 1974-1994, https:// doi.org/10.1002/2016JC012228.

Holliday, N. P., and Coauthors, 2020: Ocean circulation causes the largest freshening event for 120 years in eastern subpolar North Atlantic. Nat. Commun., 11, 585, https://doi.org/10.1038/ s41467-020-14474-y.

Huang, J., R. S. Pickart, R. X. Huang, P. Lin, A. Brakstad, and F. Xu, 2020: Sources and upstream pathways of the densest overflow water in the Nordic Seas. Nat. Commun., 11, 5389, https://doi.org/10.1038/s41467-020-19050-y.

Hunke, E. C., W. H. Lipscomb, A. K. Turner, N. Jeffery, and S. Elliott, 2015: CICE: The Los Alamos Sea Ice Model documentation and software user's manual, version 5.1. Tech. Rep. LA-CC-06-012, 116 pp., http://www.ccpo.odu.edu/ klinck/ Reprints/PDF/cicedoc2015.pdf.

Ingvaldsen, R. B., L. Asplin, and H. Loeng, 2004: The seasonal cycle in the Atlantic transport to the Barents Sea during the years 1997-2001. Cont. Shelf Res., 24, 1015-1032, https:// doi.org/10.1016/j.csr.2004.02.011.

IPCC, 2019: IPCC Special Report on the Ocean and Cryosphere in a Changing Climate. H.-O. Pörtner et al., Eds., IPCC, 755 pp., https://www.ipcc.ch/srocc/download/.

Jenkins, A., 1999: The impact of melting ice on ocean waters. J. Phys. Oceanogr., 29, 2370-2381, https://doi.org/10.1175/ 1520-0485(1999)029<2370:TIOMIO>2.0.CO;2.

JMA, 2013: JRA-55: Japanese 55-year reanalysis, monthly means and variances. Japan Meteorological Agency, accessed 5 April 2020, https://doi.org/10.5065/D60G3H5B.

Kobayashi, S., and Coauthors, 2015: The JRA-55 reanalysis: General specifications and basic characteristics. J. Meteor. Soc. Japan, 93, 5-48, https://doi.org/10.2151/jmsj.2015-001. 
Kwok, R., G. F. Cunningham, and S. S. Pang, 2004: Fram Strait Sea ice outflow. J. Geophys. Res., 109, C01009, https://doi.org/ 10.1029/2003JC001785.

Lambert, E., T. Eldevik, and P. M. Haugan, 2016: How northern freshwater input can stabilise thermohaline circulation. Tellus, 68A, 31051, https://doi.org/10.3402/tellusa.v68.31051.

Le Bras, I. A., F. Straneo, J. Holte, and N. P. Holliday, 2018: Seasonality of freshwater in the East Greenland Current system from 2014 to 2016. J. Geophys. Res. Oceans, 123, 88288848, https://doi.org/10.1029/2018JC014511.

Lecomte, O., T. Fichefet, M. Vancoppenolle, F. Domine, F. Massonnet, P. Mathiot, S. Morin, and P. Barriat, 2013: On the formulation of snow thermal conductivity in large-scale sea ice models. J. Adv. Model. Earth Syst., 5, 542-557, https://doi.org/10.1002/ jame.20039.

Lenaerts, J. T. M., and Coauthors, 2015: Representing Greenland ice sheet freshwater fluxes in climate models. Geophys. Res. Lett., 42, 6373-6381, https://doi.org/10.1002/2015GL064738.

Li, F., M. S. Lozier, and W. E. Johns, 2017: Calculating the meridional volume, heat, and freshwater transports from an observing system in the subpolar North Atlantic: Observing system simulation experiment. J. Atmos. Oceanic Technol., 34, 1483-1500, https://doi.org/10.1175/JTECH-D-16-0247.1.

Lozier, M. S., and Coauthors, 2017: Overturning in the subpolar North Atlantic program: A new international ocean observing system. Bull. Amer. Meteor. Soc., 98, 737-752, https://doi.org/ 10.1175/BAMS-D-16-0057.1.

_ , and Coauthors, 2019: A sea change in our view of overturning in the subpolar North Atlantic. Science, 363, 516-521, https:// doi.org/10.1126/science.aau6592.

Mackay, N., C. Wilson, N. P. Holliday, and J. D. Zika, 2020: The observation-based application of a Regional Thermohaline Inverse Method to diagnose the formation and transformation of water masses north of the OSNAP array from 2013 to 2015. J. Phys. Oceanogr., 50, 1533-1555, https://doi.org/10.1175/ JPO-D-19-0188.1.

Marson, J. M., P. G. Myers, X. Hu, and J. Le Sommer, 2018: Using vertically integrated ocean fields to characterize Greenland icebergs' distribution and lifetime. Geophys. Res. Lett., 45, 4208-4217, https://doi.org/10.1029/2018GL077676.

Mauritzen, C., 1996: Production of dense overflow waters feeding the North Atlantic across the Greenland-Scotland Ridge. Part II: An inverse model. Deep-Sea Res. I, 43, 807-835, https:// doi.org/10.1016/0967-0637(96)00038-6.

McDougall, T. J., and P. Barker, 2011: Getting started with TEOS10 and the Gibbs Seawater (GSW) Oceanographic Toolbox. SCOR/IAPSOWG127, 28 pp., https://www.teos-10.org/pubs/ Getting_Started.pdf.

Moon, T., D. A. Sutherland, D. Carroll, D. Felikson, L. Kehrl, and F. Straneo, 2018: Subsurface iceberg melt key to Greenland fjord freshwater budget. Nat. Geosci., 11, 49-54, https:// doi.org/10.1038/s41561-017-0018-z.

Muilwijk, M., L. H. Smedsrud, M. Ilicak, and H. Drange, 2018: Atlantic water heat transport variability in the 20th century Arctic Ocean from a global ocean model and Observations. J. Geophys. Res. Oceans, 123, 8159-8179, https://doi.org/ 10.1029/2018JC014327.

Myers, P. G., C. Donnelly, and M. H. Ribergaard, 2009: Structure and variability of the West Greenland Current in summer derived from 6 repeat standard sections. Prog. Oceanogr., 80, 93-112, https://doi.org/10.1016/j.pocean.2008.12.003.

Østerhus, S., and Coauthors, 2019: Arctic Mediterranean exchanges: A consistent volume budget and trends in transports from two decades of observations. Ocean Sci., 15, 379-399, https://doi.org/10.5194/os-15-379-2019.

Pennelly, C., X. Hu, and P. G. Myers, 2019: Cross-isobath freshwater exchange within the North Atlantic subpolar Gyre. J. Geophys. Res. Oceans, 124, 6831-6853, https://doi.org/ 10.1029/2019JC015144.

Petit, T., M. S. Lozier, S. A. Josey, and S. A. Cunningham, 2020: A new paradigm for Atlantic Ocean deep water formation. Geophys. Res. Lett., 47, e2020GL091028, https://doi.org/10.1029/ 2020GL091028.

Pickart, R. S., F. Straneo, and G. Moore, 2003: Is Labrador Sea Water formed in the Irminger Basin? Deep-Sea Res. I, 50, 2352, https://doi.org/10.1016/S0967-0637(02)00134-6.

Ricker, R., F. Girard-Ardhuin, T. Krumpen, and C. Lique, 2018: Satellite-derived sea ice export and its impact on Arctic ice mass balance. Cryosphere, 12, 3017-3032, https://doi.org/ 10.5194/tc-12-3017-2018.

Rudels, B., 2010: Constraints on exchanges in the Arctic Mediterranean - Do they exist and can they be of use? Tellus, 62A, 109-122, https://doi.org/10.1111/j.1600-0870.2009.00425.x.

_- M. Marnela, and P. Eriksson, 2008: Constraints on estimating mass, heat and freshwater transports in the Arctic Ocean: An exercise. Arctic-Subarctic Ocean Fluxes: Defining the Role of the Northern Seas in Climate, R. R. Dickson, J. Meincke, and P. Rhines, Eds., Springer, 315-341, https://doi.org/10.1007/ 978-1-4020-6774-7_14.

Saha, S., and Coauthors, 2010a: NCEP Climate Forecast System Reanalysis (CFSR) monthly products, January 1979 to December 2010. NCAR Computational and Information Systems Laboratory, accessed 2 April 2020, https://doi.org/ 10.5065/D6DN438J.

, and Coauthors, 2010b: The NCEP Climate Forecast System Reanalysis. Bull. Amer. Meteor. Soc., 91, 1015-1057, https:// doi.org/10.1175/2010BAMS3001.1.

— sion 2 (CFSv2) monthly products. NCAR Computational and Information Systems Laboratory, accessed 7 February 2020, https://doi.org/10.5065/D69021ZF.

— , and Coauthors, 2014: The NCEP Climate Forecast System version 2. J. Climate, 27, 2185-2208, https://doi.org/10.1175/ JCLI-D-12-00823.1.

Schauer, U., and M. Losch, 2019: Freshwater in the ocean is not a useful parameter in climate research. J. Phys. Oceanogr., 49, 2185-2208, https://doi.org/10.1175/JPO-D-19-0102.1.

_- A. Beszczynska-Möller, W. Walczowski, E. Fahrbach, J. Piechura, and E. Hansen, 2008: Variation of measured heat flow through the Fram Strait between 1997 and 2006. Arctic-Subarctic Ocean Fluxes: Defining the Role of the Northern Seas in Climate, R. R. Dickson, J. Meincke, and P. Rhines, Eds., Springer, 65-85, https://doi.org/10.1007/9781-4020-6774-7_4.

Seland, Ø., and Coauthors, 2020: The Norwegian Earth System Model (NorESM2) and key climate response of CMIP6 DECK, historical, and scenario simulations. Geosci. Model Dev., 13, 6165-6200, https://doi.org/10.5194/GMD-13-6165-2020.

Shepherd, A., and Coauthors, 2020: Mass balance of the Greenland Ice Sheet from 1992 to 2018. Nature, 579, 233-239, https:// doi.org/10.1038/s41586-019-1855-2.

Smedsrud, L. H., and Coauthors, 2013: The role of the Barents Sea in the Arctic climate system. Rev. Geophys., 51, 415-449, https://doi.org/10.1002/rog.20017.

Spreen, G., S. Kern, D. Stammer, and E. Hansen, 2009: Fram Strait sea ice volume export estimated between 2003 and 2008 from 
satellite data. Geophys. Res. Lett., 36, L19502, https://doi.org/ 10.1029/2009GL039591.

, L. Steur, D. Divine, S. Gerland, E. Hansen, and R. Kwok, 2020: Arctic Sea ice volume export through Fram Strait from 1992 to 2014. J. Geophys. Res. Oceans, 125, e2019JC016039, https://doi.org/10.1029/2019JC016039.

Stigebrandt, A., 1985: On the hydrographic and ice conditions in the northern North Atlantic during different phases of a glaciation cycle. Palaeogeogr. Palaeoclimatol. Palaeoecol., 50, 303-321, https://doi.org/10.1016/0031-0182(85)90074-4.

Stommel, H., 1961: Thermohaline convection with two stable regimes of flow. Tellus, 11A, 327-347, https://doi.org/10.3402/ tellusa.v13i2.9491.

Stroeve, J., and D. Notz, 2018: Changing state of Arctic sea ice across all seasons. Environ. Res. Lett., 13, 103001, https:// doi.org/10.1088/1748-9326/aade56.

Suzuki, T., D. Yamazaki, H. Tsujino, Y. Komuro, H. Nakano, and S. Urakawa, 2018: A dataset of continental river discharge based on JRA-55 for use in a global ocean circulation model. J. Oceanogr., 74, 421-429, https://doi.org/10.1007/s10872-0170458-5.

Tsubouchi, T., and Coauthors, 2012: The Arctic Ocean in summer: A quasi-synoptic inverse estimate of boundary fluxes and water mass transformation. J. Geophys. Res., 117, C01024, https://doi.org/10.1029/2011JC007174.

— , and Coauthors, 2018: The Arctic Ocean seasonal cycles of heat and freshwater fluxes: Observation-based inverse estimates. J. Phys. Oceanogr., 48, 2029-2055, https://doi.org/ 10.1175/JPO-D-17-0239.1.

, and Coauthors, 2019: The Arctic Ocean volume, heat and fresh water transports time series from October 2004 to May 2010. PANGAEA, accessed 1 August 2020, https://doi.pangaea.de/ 10.1594/PANGAEA.909966.
K. Våge, B. Hansen, K. M. H. Larsen, and S. Østerhus, 2020: Increased ocean heat transport into the Arctic Mediterranean over the period 1993-2016. Nat. Climate Change, 11, 21-26, https://doi.org/10.1038/s41558-020-00941-3.

Tsujino, H., and Coauthors, 2018: JRA-55 based surface dataset for driving ocean-sea-ice models (JRA55-do). Ocean Modell., 130, 79-139, https://doi.org/10.1016/j.ocemod.2018.07.002.

von Appen, W.-J., and Coauthors, 2014: The East Greenland Spill Jet as an important component of the Atlantic Meridional Overturning Circulation. Deep-Sea Res. I, 92, 75-84, https:// doi.org/10.1016/j.dsr.2014.06.002.

Wang, H., S. Legg, and R. Hallberg, 2018: The effect of Arctic freshwater pathways on North Atlantic convection and the Atlantic meridional overturning circulation. J. Climate, 31, 5165-5188, https://doi.org/10.1175/JCLI-D-17-0629.1.

Weijer, W., and Coauthors, 2019: Stability of the Atlantic meridional overturning circulation: A review and synthesis. J. Geophys. Res. Oceans, 124, 5336-5375, https://doi.org/10.1029/2019JC015083.

Woodgate, R. A., 2018: Increases in the Pacific inflow to the Arctic from 1990 to 2015, and insights into seasonal trends and driving mechanisms from year-round Bering Strait mooring data. Prog. Oceanogr., 160, 124-154, https://doi.org/10.1016/ j.pocean.2017.12.007.

Wunsch, C., 1978: The North Atlantic general circulation west of $50^{\circ} \mathrm{W}$ determined by inverse methods. Rev. Geophys., 16, 583620, https://doi.org/10.1029/RG016i004p00583.

— 1996: The Ocean Circulation Inverse Problem. Cambridge University Press, 442 pp., https://doi.org/10.1017/CBO9780511629570.

Yashayaev, I., and R. R. Dickson, 2008: Transformation and fate of overflows in the northern North Atlantic. Arctic-Subarctic Ocean Fluxes: Defining the Role of the Northern Seas in Climate, R. R. Dickson, J. Meincke, and P. Rhines, Eds., Springer, 505526, https://doi.org/10.1007/978-1-4020-6774-7_22. 